\title{
Pathogenesis of Murine Coronavirus in the Central Nervous System
}

\author{
Susan J. Bender • Susan R. Weiss
}

Received: 2 November 2009/Accepted: 5 March 2010/Published online: 6 April 2010

(C) Springer Science+Business Media, LLC 2010

\begin{abstract}
Murine coronavirus (mouse hepatitis virus, MHV) is a collection of strains that induce disease in several organ systems of mice. Infection with neurotropic strains JHM and A59 causes acute encephalitis, and in survivors, chronic demyelination, the latter of which serves as an animal model for multiple sclerosis. The MHV receptor is a carcinoembryonic antigen-related cell adhesion molecule, CEACAM1a; paradoxically, CEACAM1a is poorly expressed in the central nervous system (CNS), leading to speculation of an additional receptor. Comparison of highly neurovirulent JHM isolates with less virulent variants and the weakly neurovirulent A59 strain, combined with the use of reverse genetics, has allowed mapping of pathogenic properties to individual viral genes. The spike protein, responsible for viral entry, is a major determinant of tropism and virulence. Other viral proteins, both structural and nonstructural, also contribute to pathogenesis in the CNS. Studies of host responses to MHV indicate that both innate and adaptive responses are crucial to antiviral defense. Type I interferon is essential to prevent very early mortality after infection. CD8 T cells, with the help of CD4 $\mathrm{T}$ cells, are crucial for viral clearance during acute disease and persist in the CNS during chronic disease. B cells are necessary to prevent reactivation of virus in the CNS following clearance of acute infection. Despite advances in understanding of coronavirus pathogenesis, questions re-
\end{abstract}

Grant support: This study was made possible by the following grant support: NIH AI60021, NIH NS54695, National Multiple Sclerosis Society RG 3843A6/1, and NIH T32 NS007180.

S. J. Bender $\cdot$ S. R. Weiss $(\bowtie)$

Department of Microbiology,

University of Pennsylvania School of Medicine,

36th Street and Hamilton Walk,

Philadelphia, PA 19104-6076, USA

e-mail: weisssr@mail.med.upenn.edu main regarding the mechanisms of viral entry and spread in cell types expressing low levels of receptor, as well as the unique interplay between virus and the host immune system during acute and chronic disease.

Keywords murine coronavirus · virus-induced encephalitis · virus-induced demyelination . viral neuropathogenesis

\section{Introduction}

The family Coronaviridae is comprised of large, enveloped, RNA viruses that induce a variety of diseases in avian and mammalian species, including humans, poultry, livestock, and domestic animals. Coronaviruses, along with toroviruses and roniviruses, are members of the order Nidovirales ("nido" meaning "nest"), so named because of the nested set of subgenomic RNAs generated during the life cycle of these viruses (Gorbalenya et al. 2006). Coronaviruses are typically categorized into three groups based on antigenic similarity, with viruses in all groups being able to infect a range of different host species. Several human coronaviruses have been identified, including the mild respiratory pathogens HCoV-229E (Hamre and Procknow 1966) and HCoV-OC43 (McIntosh et al. 1967), an etiologic agent of croup known as HCoV-NL63 (Chiu et al. 2005; van der Hoek et al. 2005), and most notably SARS-CoV, the causative agent of severe acute respiratory syndrome (SARS; Drosten et al. 2003; Ksiazek et al. 2003; Peiris et al. 2003; Osterhaus et al. 2004). While coronaviruses are commonly regarded as being highly species-specific, the recent emergence of SARS-CoV in humans has brought renewed awareness to the potential for cross-species virus transmission from animal reservoirs. 
Perhaps the best-studied member of the Coronaviridae is the murine coronavirus known as mouse hepatitis virus (MHV). Despite its name, not all strains of MHV are hepatotropic, with individual isolates inducing respiratory, enteric, or neurologic disease alone or in combination with hepatitis (Weiss and Navas-Martin 2005). While enteric strains are typically responsible for MHV outbreaks in housed rodent colonies (Homberger et al. 1998), the most frequently studied are the neurotropic strains due to their ability to induce acute encephalomyelitis with or without chronic demyelination. These neurotropic strains differ widely in terms of cellular tropism, spread throughout the central nervous system (CNS), host immune response, and disease outcome, making them useful for analysis of viral and host determinants of neurovirulence (Weiss and NavasMartin 2005).

The RNA genome of MHV is single-stranded, positivesense, and approximately $31 \mathrm{~kb}$ in length (Fig. 1; Lai and Stohlman 1978; Lee et al. 1991). The 5' two thirds of the genome (ORF1a and ORF1b) encode the viral replicase as well as an assortment of enzymes and other nonstructural proteins, while the $3^{\prime}$ one third of the genome (ORFs 2-7) largely encodes the structural proteins of the virion. MHV binds to a target cell via interaction of the spike glycoprotein with its cellular receptor CEACAM1a (Williams et al. 1991) and fuses either at the cell surface or from within endosomes, likely depending on target cell type and MHV strain

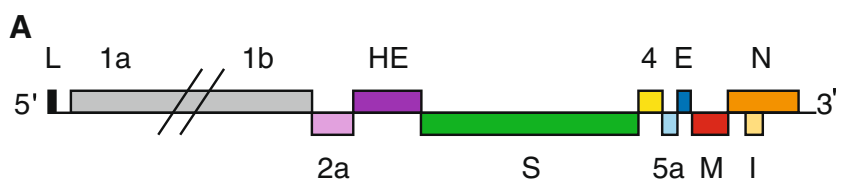

B

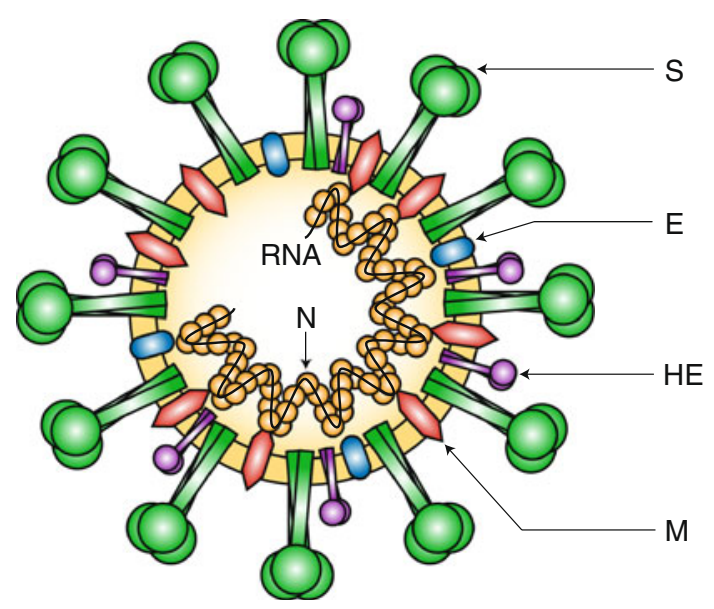

Fig. 1 A Genome organization and B virion structure of MHV. $L$ leader; ORF1a/1b, replicase; structural genes/proteins: $H E$ hemagglutinin-esterase; $S$ spike; $E$ envelope; $M$ membrane; $N$ nucleocapsid; $I$ internal. ORFs $2 \mathrm{a}, 4$, and 5 a encode nonstructural proteins
(Gallagher et al. 1991; Kooi et al. 1991; Nash and Buchmeier 1997). Following entry, viral replication occurs in the cytoplasm. Nascent nucleocapsids acquire their lipid envelopes and surface proteins via budding through internal membranes of the ER/Golgi, and newly formed virions are released at the cell surface (de Haan and Rottier 2005).

\section{Model and strains}

Two MHV strains commonly used to study coronavirusinduced CNS disease are the highly neurovirulent JHM strain and the more neuroattenuated but demyelinating A59 strain (Table 1). Neuroattenuated variants of JHM are also common. While highly neurovirulent strains, such as JHM.SD, cause severe and uniformly lethal encephalitis in naive mice, more neuroattenuated strains, such as A59 and some JHM variants, induce a less severe encephalomyelitis followed by chronic demyelination (Fig. 2; Weiss and Navas-Martin 2005). For this reason, MHV infection is commonly studied as a model for the human demyelinating disease multiple sclerosis. The JHM strain, named for Professor John Howard Mueller, was initially isolated by Cheever, Bailey, and colleagues in 1949 from the brain of a paralyzed mouse and shown to induce encephalitis with extensive destruction of myelin (Bailey et al. 1949; Cheever et al. 1949). Dr. Leslie Weiner later serially passaged this virus multiple times through mouse brains (Weiner 1973; Weiner et al. 1973). Most JHM isolates used since, including those described below, were derived from this mouse-passaged virus. The A59 strain was isolated independently in 1961 from a mouse with leukemia (Manaker et al. 1961).

CNS disease induced by neurotropic MHV strains can be loosely divided into two phases, acute encephalitis and chronic demyelinating disease (Fig. 2). Following intracranial or intranasal inoculation, mice develop a mild to severe encephalomyelitis, characterized by infiltration of a variety of inflammatory cells. Viral titers typically peak at day 5 post-infection and then begin to decline (Leparc-Goffart et al. 1998), with infectious virus becoming undetectable by approximately 2 weeks post-infection (Matthews et al. 2001). Innate immune responses are apparent within the first few days of infection and then give way to adaptive immunity. CD8 T cells, which play a dominant role in controlling virus replication, are most numerous in the brain at day 7 post-infection, coinciding with viral clearance (Williamson et al. 1991). However, despite clearance of infectious virus, viral RNA persists in the CNS and demyelination, largely immune-mediated, becomes evident around 4 weeks post-infection (Lavi et al. 1984a, b). A notable exception to this disease course is CNS infection with the highly neurovirulent JHM isolates, particularly 


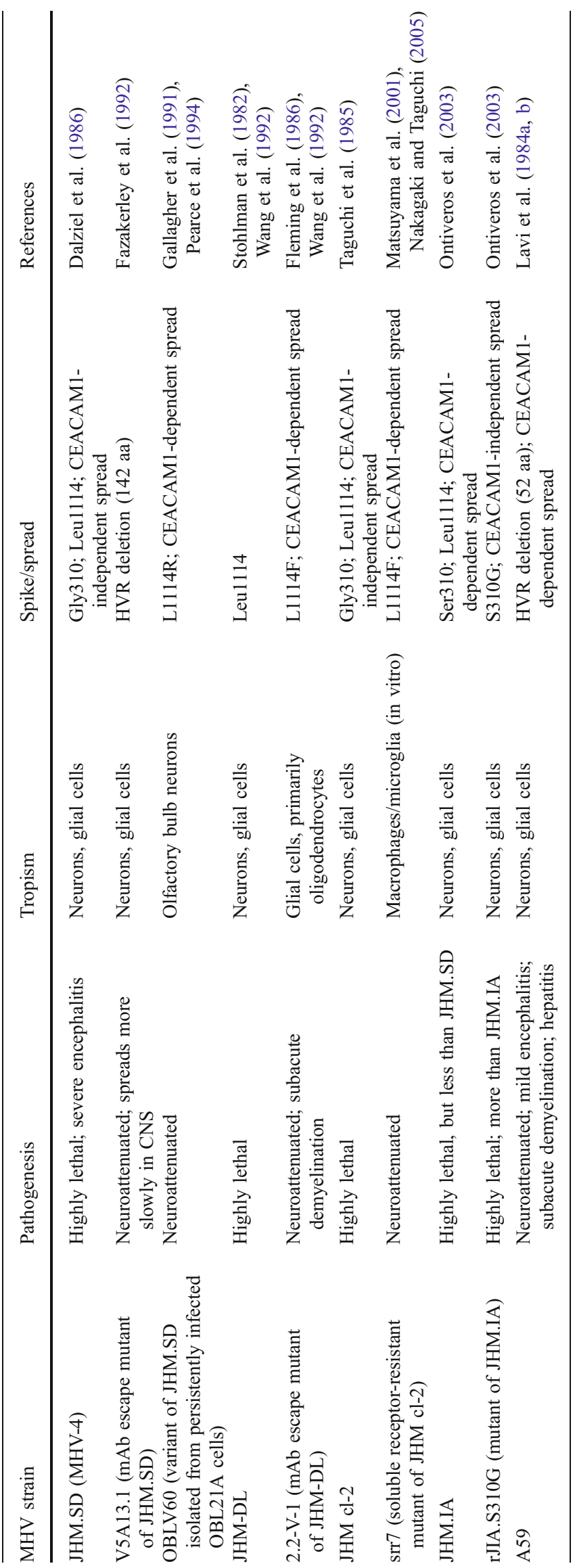




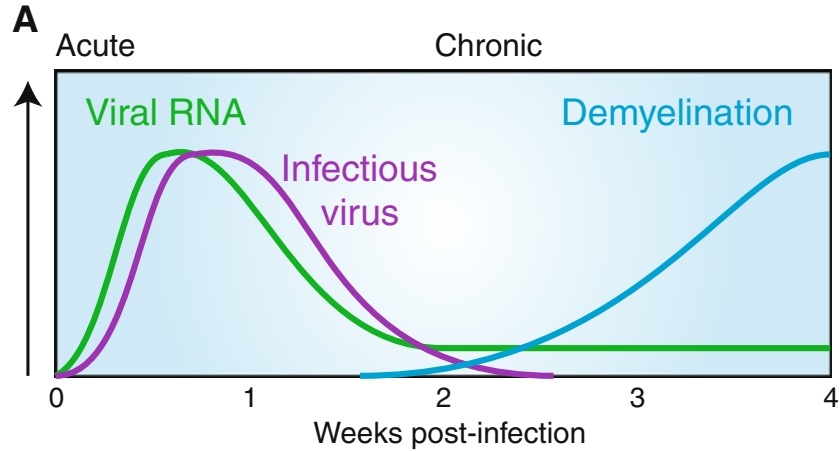

B

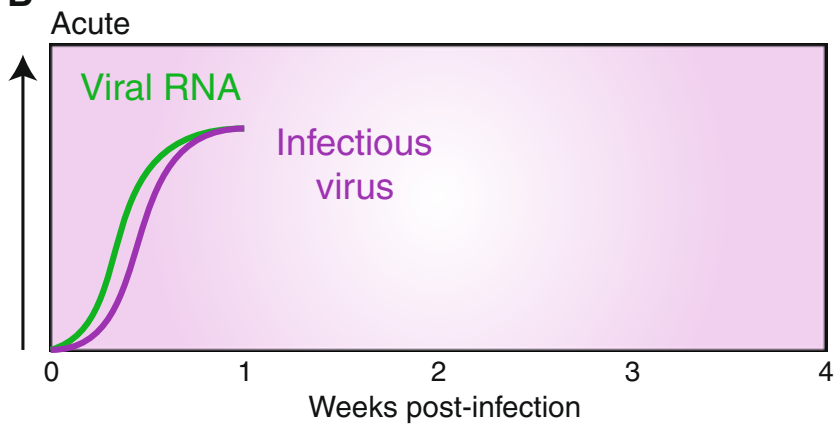

Fig. 2 Kinetics of CNS disease following intracranial inoculation of A demyelinating MHV strains or $\mathbf{B}$ the highly neurovirulent JHM.SD strain. JHM.SD-infected mice succumb to acute CNS disease by 1 week post-infection

JHM.SD, which grow to increasing titers and induce severe encephalitis that is lethal within the first week of infection (Fig. 2; Ontiveros et al. 2003). The degree of viral spread throughout the brain and spinal cord, tropism of virus for individual CNS cell types, and dissemination of virus to other organs is largely dependent on viral strain (Table 1).

\section{Receptor and tropism}

The primary cellular receptor for MHV has been identified as CEACAM1a (also referred to as mmCGM1, BGP1a, and CD66a) belonging to the carcinoembryonic antigen family of cell adhesion molecules within the immunoglobulin superfamily (Williams et al. 1990, 1991). CEACAM1a is a multifunctional protein shown to play diverse roles in a variety of cellular processes, including intercellular adhesion, tumor suppression, angiogenesis, and immune cell signaling (Gray-Owen and Blumberg 2006; Kuespert et al. 2006). The ceacaml gene is highly conserved among mammalian species, and human CEACAM1 proteins serve as receptors for a variety of pathogens, including Neisseria species and Haemophilus influenzae. In the mouse, ceacam 1 exists in two allelic forms, ceacam $1 a$ and ceacam $1 b$, and the particular ceacam 1 allele expressed largely determines susceptibility of individual mouse strains to MHV; mouse strains expressing ceacam 1a, including C57BL/6 and $\mathrm{BALB} / \mathrm{c}$, are highly susceptible to MHV infection whereas strains homozygous for ceacam $1 b$, such as SJL, are resistant (Dveksler et al. 1993b).

Ceacam 1 a transcripts typically undergo alternative splicing, giving rise to four distinct splice variants and protein isoforms in the mouse (Fig. 3). These murine CEACAM1a isoforms contain either two or four extracellular immunoglobulin-like domains linked by a transmembrane domain to either a short (10 aa) or long (73 aa) cytoplasmic tail (McCuaig et al. 1992, 1993). Using recombinant CEACAM1a constructs with deletions within the extracellular domains, the site of MHV binding was shown to be within the N-terminal domain (D1; Dveksler et al. 1993a). This N-terminal domain is present in all four murine CEACAM1a isoforms; thus, all serve as functional MHV receptors. Interestingly, long-tailed CEACAM1a isoforms contain phosphorylatable tyrosine residues within immunoreceptor tyrosine-based inhibitory motifs that have been shown to participate in protein-protein interactions and downstream signaling cascades in a variety of cell types, including $\mathrm{T}$ cells (Chen et al. 2008) and dendritic cells (Kammerer et al. 2001). Thus, it is tempting to speculate that MHV binding to long-tailed isoforms may trigger or modulate intracellular signaling pathways in ways that virus binding to short-tailed isoforms may not.

While CEACAM1a is commonly regarded as the sole in vivo receptor for MHV, several lines of evidence suggest the presence of an alternative receptor or mechanism of
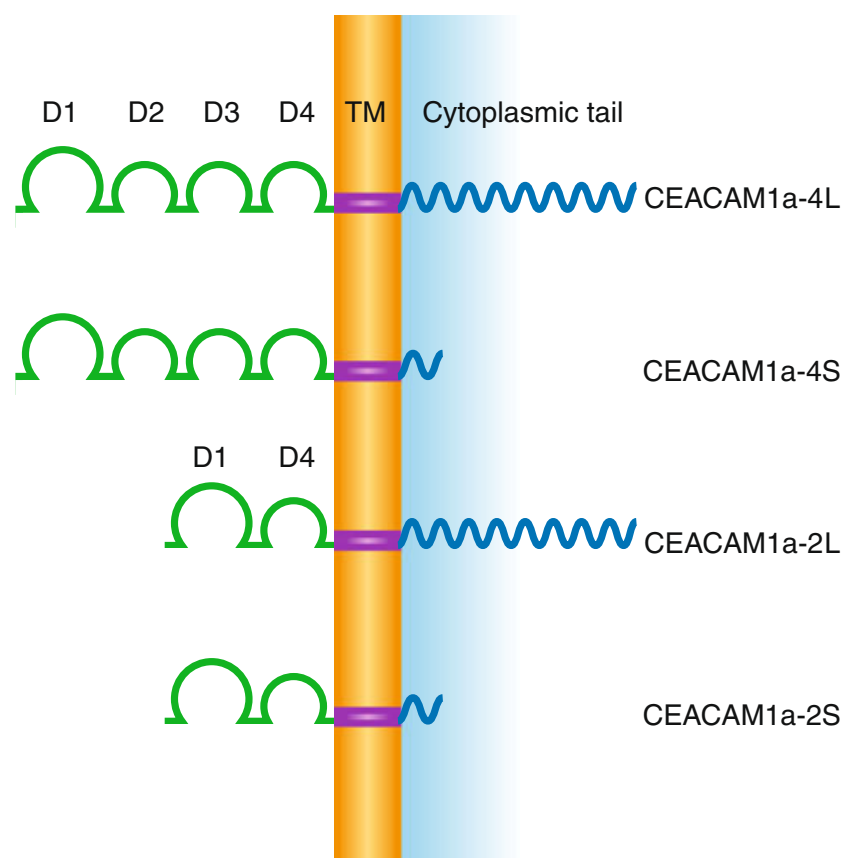

Fig. 3 Structural isoforms of the MHV receptor CEACAM1a. D extracellular immunoglobulin-like domain, TM transmembrane domain, $L$ long cytoplasmic tail, $S$ short cytoplasmic tail 
viral infection. Despite the high predilection of some MHV strains for cells of the CNS, expression of CEACAM1a is relatively low in neural tissue compared to other MHV targets, such as liver and intestine (Godfraind et al. 1995). CEACAM1a is highly expressed on epithelia, endothelia, and cells of hematopoietic origin, including macrophages, B cells, and activated T cells (Coutelier et al. 1994; Godfraind et al. 1995; Nakajima et al. 2002). In the brain, only endothelial cells and microglia have been shown to express CEACAM1a protein (Godfraind et al. 1997; Ramakrishna et al. 2004). Yet, perhaps paradoxically, many neurotropic MHV strains are able to infect a wide range of CNS cell types in addition to endothelial cells and microglia, including neurons, astrocytes, and oligodendrocytes. It has been suggested for the highly neurovirulent JHM cl-2 strain that CEACAM1a-positive microglia serve as the initial target of infection and that virus subsequently spreads to other CNS cell types in a CEACAM1aindependent manner; a soluble receptor-resistant mutant of cl-2 known as srr7 (Matsuyama et al. 2001) cannot spread without CEACAM1a and is thus restricted to microglia in mixed neural cultures (Nakagaki and Taguchi 2005). Curiously, strain A59, which has also been shown to depend on CEACAM1a for spread (Tsai et al. 2003a; unpublished data), infects a variety of CNS cell types in vivo in addition to microglia. These seemingly disparate results raise the question as to whether CNS cell types other than microglia express low levels of CEACAM1a that are simply not detected by routine methods or whether some neurotropic MHV strains may use an alternative mechanism to enter these cells. Ongoing studies using primary cell cultures and purified CNS cell populations are being carried out in our laboratory to elucidate the expression patterns of known MHV receptor genes in individual CNS cell types.

The recent generation of a knockout mouse deficient in ceacam 1a (ceacam1a-/-) by targeted deletion of the exon encoding the $\mathrm{N}$-terminal domain has made it possible to evaluate MHV infection in the absence of CEACAM1a (Hemmila et al. 2004). Interestingly, two neurotropic MHV strains, A59 and JHM.SD, differ in their ability to cause CNS disease in these mice following intracranial inoculation. JHM.SD, a highly neurovirulent isolate previously shown to spread cell-to-cell in vitro in a CEACAM1aindependent manner, was able to cause lethal CNS disease in ceacam1a-/- mice, albeit at considerably higher doses than are required in wild-type C57BL/6 mice, whereas doses as high as one million PFU of A59 were unable to cause CNS disease; the ability of JHM.SD to cause disease in these mice was mapped to the spike gene (Hemmila et al. 2004; Miura et al. 2008). While this finding is intriguing, it is unclear whether the inability of A59 to cause disease in ceacam 1a-/- mice is due to a lack of initial infection or deficiency in cell-to-cell spread in the CNS in the absence of CEACAM1a. In vitro studies are underway to distinguish these possibilities.

Several alternative receptors have been identified and shown to mediate MHV infection in nonmurine cells when overexpressed in vitro. An additional ceacam gene, ceacam2 (bgp2), is uniquely expressed in the mouse and can facilitate infection with A59, JHM, and the hepatotropic MHV-3 strain when transiently transfected into hamster cells, though much less efficiently than ceacam la; ceacam 2 messenger RNA (mRNA) was also shown to be expressed in brain tissue (Nedellec et al. 1994). The alternative ceacam $1 b$ allele expressed by MHV-resistant mice can similarly mediate infection with A59 when overexpressed in vitro (Dveksler et al. 1993b). While the relative efficiencies of these alternative receptors are unclear, the decreased infection efficiency observed is likely attributable to sequence differences within the MHV binding site in the N-terminal domain. Yet another putative receptor, psg16 (bCEA), belonging to the more distantly related pregnancy-specific glycoprotein family, was identified in the brain due to its weak homology with ceacam 1a; curiously, psg16 was reported to function in vitro as a receptor for A59 but not JHM (Chen et al. 1995). Still, it remains possible that an alternative receptor used by MHV in the brain may be completely unrelated to CEACAM1a, making its identification more difficult. Furthermore, the possibility that a traditional receptor molecule is not required to trigger MHV fusion cannot be excluded as some MHV strains, like JHM.SD, are inherently more fusogenic or may have acquired unique mechanisms to spread to cells expressing low levels of or no CEACAM1a.

\section{Viral proteins and pathogenesis}

The availability of reverse genetics, in combination with numerous MHV strains with different biological properties, has made it possible to confirm and extend previous correlative studies and more rigorously map the viral determinants of tropism and virulence. Two reverse genetics systems have been established for the selection of recombinant MHV strains. Targeted recombination, developed by Dr. Paul Masters (Koetzner et al. 1992; Kuo et al. 2000), allows the exchange of viral genes and insertion of site-directed targeted mutations within the $3^{\prime}$ one third of the genome encoding the viral structural genes (Fig. 1). The development of a full-length MHV complementary DNA clone, achieved by Dr. Ralph Baric (Yount et al. 2002), has extended these genetic analyses to include the $5^{\prime}$ two thirds of the genome containing the replicase gene.

Spike (S) There had been considerable evidence accumulated over many years to demonstrate that the spike protein 
is the major determinant of MHV tropism and pathogenicity. These data were confirmed and extended by more recent experiments carried out using both reverse genetics systems. It is not surprising that the spike, which interacts with the receptor CEACAM1a to mediate entry as well as cell-to-cell fusion, is crucial in determining the extent of viral spread within the CNS. Characterization of isogenic recombinant MHV strains differing only in spike has definitively demonstrated the important role of spike in determining neurovirulence during infection in the mouse (Phillips et al. 1999, 2002; Navas and Weiss 2003; Iacono et al. 2006). The replacement of the A59 spike gene with the spike of JHM.SD (rA59/S $\mathrm{S}_{\mathrm{JHM}}$ ) confers high neurovirulence on the resulting virus (Phillips et al. 1999; Navas and Weiss 2003). These studies have also demonstrated, perhaps unexpectedly, that a chimeric recombinant virus expressing the spike of the hepatotropic A59 within the background of the nonhepatotropic JHM.SD ( $\left.\mathrm{rJHM} / \mathrm{S}_{\mathrm{A} 59}\right)$ cannot induce hepatitis (Navas and Weiss 2003). Thus, spike alone is unable to dictate organ tropism.

The spike, a type I membrane protein, is synthesized as a $180-\mathrm{kDa}$ precursor protein, co-translationally glycosylated, and processed by a furan-like enzyme into two approximately $90-\mathrm{kDa}$ noncovalently linked subunits, the aminoterminal S1 and the carboxyl-terminal S2 (Fig. 4; Frana et al. 1985; Luytjes et al. 1988). Spike is expressed on the virion membrane as a trimer in which the $\mathrm{S} 1$ subunits form a globular head structure and the S2 subunits form a transmembrane stalk (Fig. 1). There are at least three domains within the spike that have been shown to influence pathogenic outcome: (1) the receptor binding domain (RBD) contained within the N-terminal 330 amino acids, (2) the hypervariable region (HVR) within S1, and (3) the heptad repeat domains (HR1 and HR2) within S2 (Fig. 4).

Mutations within the RBD have an influence on tropism and virulence. While JHM.SD and JHM.IA are both highly neurovirulent, the enhanced neurovirulence of JHM.SD can

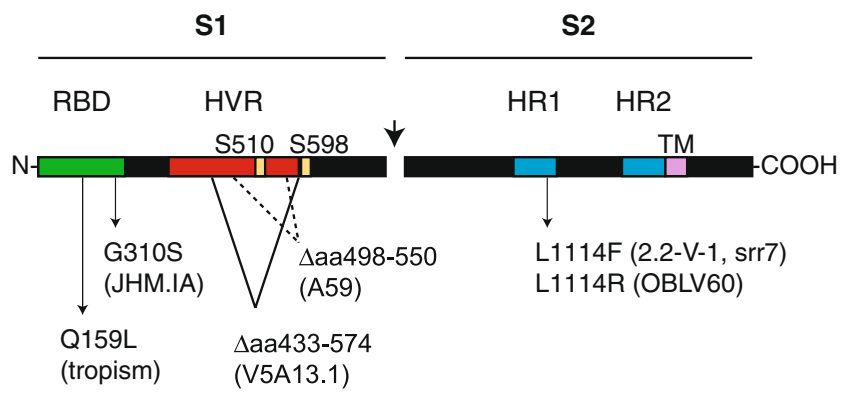

Fig. 4 Structure of the JHM.SD spike glycoprotein. $R B D$ receptor binding domain, $H V R$ hypervariable region, $H R$ heptad repeat domain, $T M$ transmembrane domain; S510 and S598, H- $2^{\mathrm{b}}$-restricted T cell epitopes. Large arrowhead indicates cleavage site yielding S1 and S2 subunits. Mutations/deletions found in other neurotropic MHV strains are indicated below structure be mapped to a single amino acid difference within the $\mathrm{RBD}$ at residue 310 (Gly rather than Ser), as the introduction of a S310G substitution within the JHM.IA spike confers increased virulence on a recombinant JHM.IA. Furthermore, this Gly substitution at position 310 is associated with the ability to spread cell-to-cell in a CEACAM1a-independent manner (Ontiveros et al. 2003). Characterization of viruses in which the RBDs of A59 and JHM.SD were exchanged further demonstrated that the ability to carry out CEACAM1a-independent spread required both the RBD and the rest of the spike to be derived from JHM (Tsai et al. 2003a). Interestingly, a single amino acid substitution, Q159L, within the RBD eliminates the ability of A59 to infect the liver while having no measurable effect on neurovirulence (Leparc-Goffart et al. 1997; Leparc-Goffart et al. 1998).

Among the many JHM isolates, high neurovirulence is correlated with the presence of a long HVR within S1 (Fig. 4). There are several JHM isolates with a similar long spike (Table 1), including JHM.SD (Dalziel et al. 1986; Ontiveros et al. 2003), JHM cl-2 (Taguchi et al. 1985), and JHM-DL (Wang et al. 1992). The extremely high neurovirulence of these viruses is due, at least in part, to their ability to induce cell-to-cell fusion and viral spread in the absence of the receptor CEACAM1a (Gallagher et al. 1992, Dalziel et al. 1986; Gallagher and Buchmeier 2001). This lack of requirement for CEACAM1a is associated with a less stable association of $\mathrm{S} 1$ and $\mathrm{S} 2$ such that the conformational changes that lead to fusion are more easily triggered, even in the absence of CEACAM1a (Gallagher and Buchmeier 2001; Krueger et al. 2001). The important role of the HVR in neurovirulence is further supported by the observation that the neuroattenuated phenotypes of a group of monoclonal antibody escape variants of JHM.SD, such as V5A13.1 (Fazakerley et al. 1992), are associated with single site mutations and/or deletions within the HVR (Dalziel et al. 1986; Gallagher et al. 1990; Phillips et al. 2001). Consistent with the comparison of different JHM spikes, the genome of the neuroattenuated A59 strain encodes a large deletion (52 aa) within the HVR. However, replacement of the HVR of A59 with that of JHM.SD did not confer a highly neurovirulent phenotype to the virus (Phillips et al. 2001), suggesting that cooperation of several regions of spike, including the long HVR, is likely required for the high neurovirulence conferred by the JHM.SD spike.

Single amino acid substitutions in the heptad repeat (HR) domains within $\mathrm{S} 2$ have been shown to have dramatic effects on pathogenesis as well (Fig. 4). This region of the spike undergoes conformational changes during the fusion process, and thus, it is not surprising that it plays a role in pathogenic phenotype. Amino acid substitutions at position 1114 within the heptad repeat 1 (HR1) of the JHM spike 
(L1114R/F) are particularly intriguing in that they have been reported in multiple studies and in association with several mutant phenotypes (Table 1). The spike protein of the OBLV60 mutant of JHM.SD, which is restricted in replication to the murine olfactory bulbs, contains three amino acid substitutions within HR1 that have been associated with the requirement for low $\mathrm{pH}$ to induce fusion. One of these substitutions alone, L1114R, is sufficient to confer neuroattenuation and restriction to the olfactory bulbs (Gallagher et al. 1991; Tsai et al. 2003b; Pearce et al. 1994). A L1114F substitution has also been identified in the spike of the 2.2-V-1 glial-tropic variant of JHM-DL (Wang et al. 1992) and in the spike of the highly attenuated soluble receptor-resistant mutant srr7 derived from JHM cl-2 (Saeki et al. 1997, 1998). These substitutions are associated with an inability to induce CEACAM1a-independent cell-to-cell fusion as well as neuroattenuation (Matsuyama and Taguchi 2002a, b; Taguchi and Matsuyama 2002). Interestingly, viruses expressing the JHM spike with a L1114F substitution have lost their tropism for neurons while the OBLV60 mutant, expressing a spike carrying the L1114R substitution, can readily infect neurons of the olfactory bulb in vivo. Thus, small changes within the HR domains, even different substitutions of the same residue, may result in alterations in spike/receptor interaction and subsequent virus entry and pathogenesis in vivo.

Hemagglutinin-esterase (HE) The nonessential HE glycoprotein forms a second, smaller spike on the envelope of some coronaviruses, including some MHV strains (Fig. 1; Yokomori et al. 1989; Kienzle et al. 1990; Yokomori et al. 1991; Smits et al. 2005). The HE protein has sialic acidbinding and acetyl esterase (or receptor destroying) activities, both of which could potentially contribute to viral entry and/or release from the cell surface via interaction with sialic acid-containing moieties. Thus, it had long been speculated that HE may play a role in acute and/or chronic MHV disease, either as a determinant of organ and/or cellular tropism (Yokomori et al. 1992, 1993, 1995) or to aid in spread of the virus (Kienzle et al. 1990). Consistent with this hypothesis, some of the highly neurovirulent JHM isolates express an HE protein while HE is not expressed by the tissue culture-adapted and weakly neurovirulent A59 strain (Shieh et al. 1989). There were early studies both supporting and arguing against a role for HE in MHV pathogenesis (Taguchi et al. 1986; LaMonica et al. 1991; Yokomori et al. 1992, 1993, 1995). However, these studies were not able to distinguish between the effects of HE and the influence of other genes in the comparison of various MHV isolates. It is clear that expression of the viral HE glycoprotein is not essential for virulence in the CNS, as evidenced by the fact that A59 causes mild encephalitis as well as chronic demyelinating disease without expressing HE. More recently, a role for HE in the spread of virus in the CNS was demonstrated by comparison of isogenic recombinant viruses expressing a wild-type HE protein, a full-length HE protein in which the esterase activity had been eliminated, and a virus expressing a truncated HE polypeptide (Kazi et al. 2005). The viruses that expressed full-length HE polypeptides (with or without a functional esterase activity) were more virulent when inoculated intracranially into mice and spread more extensively in the CNS compared to viruses expressing a truncated HE polypeptide. Thus, perhaps surprisingly, enhanced virulence does not require an intact esterase activity, suggesting that HE may instead enhance virus attachment and/or spread via binding to sialic acid-containing molecules. Since expression of the MHV receptor CEACAM1a is relatively low in the brain, we speculate that HE interaction with cell surface molecules may enhance attachment to one or more neural cell types.

Membrane (M) and small envelope (E) In addition to spike, all coronaviruses encode two additional transmembrane proteins, $\mathrm{M}$ and $\mathrm{E}$ (Fig. 1). $\mathrm{M}$, the most abundant membrane protein in the virion, may be $\mathrm{N}$ - or Oglycosylated, depending on the viral strain. Interestingly, the glycosylation state of $M$ has been shown to affect the induction of type I interferon (IFN- $\alpha / \beta)$. The $M$ protein of a porcine coronavirus, transmissible gastroenteritis virus (TGEV), induces type I interferon, and mutations that reduce glycosylation of $\mathrm{M}$ decrease this activity (Laude et al. 1992). While the M protein of MHV is O-glycosylated, glycosylation is not essential for either viral assembly or infectivity; furthermore, the glycosylation state of $\mathrm{M}(\mathrm{N}-$, O-, or no glycosylation) does not affect MHV replication in vitro. However, the glycosylation type may affect the ability of MHV $\mathrm{M}$ to induce IFN- $\alpha$ in vitro and also to replicate in the mouse liver (de Haan et al. 2003).

The coronavirus $\mathrm{E}$ protein is an integral membrane protein (Yu et al. 1994) that plays an important role in viral assembly (Vennema et al. 1996). Surprisingly, E is not an essential protein; however, a recombinant MHV lacking E expression replicates very inefficiently, consistent with the important role of $\mathrm{E}$ in production of infectious virus (Kuo and Masters 2003). E proteins of several coronaviruses, including MHV, have been demonstrated to have ion channel activity (Wilson et al. 2006). While the role of this channel activity is unknown, it has been speculated to function at the site of budding to enhance viral assembly and morphogenesis. A recent study proposes that the E protein of SARS-CoV may disrupt ion homeostasis in the host cell and that pro-apoptotic effects attributed to E (An et al. 1999) could result from membrane depolarization resulting from such ionic disturbances (Pervushin et al. 2009). 
Nucleocapsid $(N)$ The N protein of MHV plays roles in virion structure, in vitro virus replication, and CNS pathogenesis. $\mathrm{N}$ plays structural roles by both complexing with genomic RNA to form the capsid (Sturman et al. 1980) and interacting with the viral membrane protein (M) during virion assembly (Fig. 1; Hurst et al. 2005). N plays an important role in enhancing efficiency of transcription (Compton et al. 1987) and significantly enhances recovery of infectious virus from cells transfected with genome length synthetic RNA (Grossoehme et al. 2009). N has also been implicated to play a role in translation of viral mRNA (Tahara et al. 1998). Furthermore, MHV $\mathrm{N}$ has been reported to associate with microtubules in a neuronal cell line in vitro (Pasick et al. 1994), suggesting a possible role for $\mathrm{N}$ in trafficking and axonal transport. Finally, the $\mathrm{N}$ protein of A59 was shown to antagonize type I interferon by blocking RNase L activity in vitro when expressed from a recombinant vaccinia virus (Ye et al. 2007).

We recently investigated the role of MHV nucleocapsid in CNS pathogenesis. In vivo studies of recombinant chimeric JHM/A59 viruses demonstrated that the JHM.SD $\mathrm{N}$ is a determinant of high neurovirulence, as a chimeric virus expressing the JHM N within the A59 background is significantly more neurovirulent than the parental A59 (Cowley et al. 2010). While the mechanism of this enhanced neurovirulence is unclear, our data suggest that it is unlikely to involve enhanced axonal transport or the role of $\mathrm{N}$ as an interferon antagonist. Interestingly, $\mathrm{N}$ has been implicated as an important determinant of MHV-3 liver pathogenesis. However, this effect occurs via induction of fibrinogen-like protein 2 (fgl2; Parr et al. 1995; Ning et al. 1999, 2005) by the N proteins of hepatotropic MHV-3 and A59 strains, and there is no evidence to suggest that fgl2 plays a role in CNS pathogenesis.

Nonstructural proteins Several nonstructural proteins, including three replicase proteins (nsp1, nsp3, and nsp14) and ns2 (encoded in ORF2a), have been implicated in MHV pathogenesis (Fig. 1).

The N-terminal cleavage product of the polyprotein encoded by the MHV replicase gene, known as nsp1 (p28), was shown to have a role in pathogenesis in vivo. While an nsp1 A59 mutant (MHV-nsp1 $\Delta 99$ ) replicated with similar kinetics and to a similar titer as wild-type A59 virus in murine $17 \mathrm{Cl}-1$ fibroblasts, it was attenuated in its ability to replicate in the liver and cause hepatitis (Zust et al. 2007; Narayanan et al. 2008). There are data suggesting that the nsp1 proteins of both MHV and SARS-CoV have the ability to inhibit the synthesis and/or signaling activities of IFN- $\beta$ (Wathelet et al. 2007). However, since nsp1 has been reported to promote host mRNA degradation (Narayanan et al. 2008), it is difficult to conclude whether the effect on IFN- $\beta$ is a direct effect of nsp1 or indirect through its ability to degrade host cell mRNA. Nevertheless, it is clear that the nsp1 proteins of MHV and SARS-CoV are both virulence factors (Frieman et al. 2008).

Nsp3, a cleavage product of the polyprotein encoded in the ORF1a replicase gene of coronaviruses, is a large, 180 $200-\mathrm{kDa}$, multifunctional protein containing two domains shown to be virulence factors, the so called " $\mathrm{X}$ " or macro domain (ADP-ribose 1"-phosphatase or ADRP) and the papain-like protease (PLP) domain. PLP (or PLpro) will be discussed here and the " $\mathrm{X}$ " domain will be discussed below. The nsp3 protein of SARS-CoV was shown to be a type I IFN antagonist, as measured by inhibition of expression of an NF-kB-dependent reporter plasmid (Wathelet et al. 2007). The PLP of SARS-CoV and the analogous PLP-2 of MHV were also shown to have deubiquitinating activity, and it was suggested that this activity could confer a role as a type I IFN antagonist (Barretto et al. 2005; Zheng et al. 2008). Indeed, several studies have demonstrated that the PLP of SARS-CoV inhibits both the IRF3 and NF- $\mathrm{KB}$ pathways (Devaraj et al. 2007; Frieman et al. 2009). However, there are conflicting data regarding the role of MHV PLP-2 as a type I IFN antagonist (Zheng et al. 2008; Frieman et al. 2009), and it is possible that the MHV- and SARS-CoV-encoded proteases may differ in this activity.

All coronaviruses contain, within nsp3, a conserved ADRP domain (also referred to as the " $\mathrm{X}$ " or macro domain as above). Macro domains are ubiquitous and highly conserved among many viral groups and throughout all eukaryotic organisms, bacteria, and archae. The best characterized is the histone-associated MacroH2A, which plays a role in cell type-specific regulation of transcription (Changolkar et al. 2008). MHV, as well as some other group II coronaviruses, encodes the ns2 protein in ORF2a, just downstream of the replicase gene. The ns2 protein contains a domain with high homology to a superfamily of proteins known as $2 \mathrm{H}$ phosphoesterases and is thus predicted to have a 1",2"-cyclophosphodiesterase (CPD) activity (Snijder et al. 2003). Together, the putative CPD domain and the ADRP domain could potentially participate in a pathway of nucleotide processing (Gorbalenya et al. 1991; Snijder et al. 2003) in which the CPD would convert ADP-ribose-1",2"-cyclic phosphate into ADP-ribose 1" phosphate and the ADRP would convert the product of the CPD, ADP-ribose 1" phosphate, into ADP-ribose and inorganic phosphate (Putics et al. 2005, 2006b). While CPD activity has not yet been demonstrated for the MHV ns2 protein, the ADRPs of several coronaviruses (including SARS-CoV, HCoV-229E, and porcine TGEV) were demonstrated to have phosphatase activity (Putics et al. 2005, 2006a). In addition, the ADRP also has binding activity to mono- and poly-ADP-ribose, implying that it may participate in ribosylation of host cell proteins, which may promote apoptosis or necrosis (Egloff et al. 2006). 
Mutations in either the predicted catalytic residues of ns2 or the catalytic residues of the ADRP domain have been shown to cause attenuating effects on the ability of MHV to induce hepatitis while having no effect on replication in cultured fibroblasts. However, the ns 2 mutations do not appear to influence neurovirulence, and the effect of ADRP mutations on neurovirulence remains to be assessed. Interestingly, a macro domain has been implicated in Sindbis virus neuropathogenesis, though the pathway is not yet understood. The Sindbis virus nsp3 protein contains a macro domain with a very weak phosphatase activity; furthermore, the binding of poly-ADP-ribose polymerase (PARP-1) to Sindbis nsp3 outside of the macro domain is believed to regulate transcription in neuronal cells (Park and Griffin 2009a, b). Though the role of the ADRP in coronavirus replication and/or pathogenesis is poorly understood, the activities associated with macro domains may vary among coronavirus groups, as a recent report suggests that the macro domain of group I coronaviruses may differ from that of group III coronaviruses in the ability to bind ADP-ribose (Piotrowski et al. 2009).

The coronavirus replicase protein nsp14 (p59) is a $3^{\prime}-5^{\prime}$ exonuclease (ExoN) of the DEDD superfamily (Snijder et al. 2003). Interestingly, the nsp14 protein of MHV markedly increases the fidelity of transcription of viral RNA (Eckerle et al. 2007). Furthermore, a single amino acid substitution (Y6398H) 140 amino acids downstream of the last predicted exoribonuclease catalytic motif had no effect on replication in cell culture but conferred significant viral attenuation in mice (Sperry et al. 2005). The precise role of this nsp14 in pathogenesis is not yet known.

\section{Immune responses to $\mathrm{MHV}$}

Type I interferon Type I interferon (IFN- $\alpha / \beta)$ signaling is an important aspect of host defense during the early phases of MHV infection. This role is supported by several recent reports of the high mortality following MHV infection that were carried out in the absence of IFN signaling in type I interferon receptor deficient (IFNAR-/-) mice (CervantesBarragan et al. 2007; Ireland et al. 2008; Roth-Cross et al. 2008). IFNAR-/- mice inoculated intracranially with low doses of the neurotropic MHV strains A59 and JHM.SD showed dramatically accelerated clinical signs and mortality compared with wild-type C57BL/6 mice. In addition, there were increased levels of infectious virus in the brain and spinal cord (and in the case of A59, the liver) of infected IFNAR $-/-$ mice, as well as spread to other organs not usually affected, compared to wild-type mice (RothCross et al. 2008). Following intracranial inoculation of IFNAR-/- mice with the glial-tropic JHM variant $2.2-\mathrm{V}-1$, the virus was able to spread more extensively among glial cell types compared with wild-type mice as well as to neurons, a cell type not typically infected with this strain of virus. Importantly, the abrogation of IFNAR expression had little effect on the function of virus-specific CD8 T cells, illustrating the importance of the type I IFN response even in the presence of a robust $\mathrm{T}$ cell response (Ireland et al. 2008).

In contrast to the induction of type I IFN observed in vivo in the murine CNS, MHV induces type I IFN mRNA very poorly and only at very late times after infection in murine fibroblast cell lines (Roth-Cross et al. 2007, 2008). Thus, it was of interest to determine which CNS cell types produce IFN- $\beta$ in response to MHV infection. While cultured astrocytes and neurons, two major targets of MHV infection, failed to produce significant levels of IFN- $\beta$ mRNA, macrophages and microglia isolated from the CNS of infected mice were shown to produce IFN- $\beta$ protein; this result was consistent with IFN- $\beta$ mRNA expression observed in cultured primary macrophages and microglia (Roth-Cross et al. 2008). Infection of primary macrophages derived from the bone marrow of mice lacking expression of several pattern recognition receptors further demonstrated that MDA5 is a major sensor that recognizes MHV and triggers type I IFN expression in this cell type; however, it is likely that other sensors are also important for the recognition of MHV in vivo.

Cervantes-Barragan et al. (2009) showed that type I IFN signaling was most important in bone marrow-derived cells, specifically macrophages and dendritic cells, and to a much lesser extent in parenchymal cells to control viral replication and spread in a model of MHV-induced hepatitis. In contrast, these authors concluded that loss of signaling by bone marrow-derived cells did not have a significant effect on replication in the brain following intranasal inoculation. This result is in contrast to the studies described above in which IFNAR signaling was essential for control of spread of virus following intracranial inoculation (Ireland et al. 2008; Roth-Cross et al. 2008). Taken together, these data suggest that type I IFN signaling in parenchymal cells may have a variable impact on spread of virus within the brain and may depend on the route of inoculation and the initial cell types infected. This idea is supported by the observation that IFNAR expression in the glomerular layer of the olfactory bulb is essential to prevent vesicular stomatitis virus from replicating and spreading in the CNS following intranasal inoculation (Detje et al. 2009). We are currently investigating the role of type I IFN signaling in protection during MHV infection in specific CNS cell types.

Inflammatory cell infiltrate A robust innate immune response, including macrophage, neutrophil, and NK cell migration into the CNS and secretion of chemokines, develops during the first few days following MHV 
inoculation. Both the numbers and types of infiltrating cells and the chemokines secreted are dependent on MHV strain and contribute to the severity of disease, as described and reviewed elsewhere (Marten et al. 2001; Glass et al. 2002; Rempel et al. 2004b; Bergmann et al. 2006; Iacono et al. 2006; Savarin et al. 2008; Scott et al. 2008).

The highly neurovirulent JHM.SD strain is characterized by rapid spread of viral antigen through the brain accompanied by greater levels of infiltrating neutrophils and macrophages, as well as increased cellular destruction, compared to the weakly neurovirulent A59 strain (Rempel et al. 2004a, b; Iacono et al. 2006). While infiltrating neutrophils had a protective effect for animals infected with the attenuated, glial-tropic JHM variant 2.2-V-1 (Zhou et al. 2003), neutrophil depletion studies using the highly neurovirulent JHM.SD strain suggest that this cell type can serve as a destructive force within the inflamed CNS, contributing to both destruction of the brain parenchyma and maintenance of a pro-inflammatory state (Iacono et al. 2006). Not surprisingly, the observation of increased numbers of macrophages and neutrophils within the brains of JHM.SD-infected animals is consistent with higher levels of macrophage- and neutrophil-recruiting chemokines in the brain, as well as prolonged expression of IFN$\beta$, whereas A59 infection is characterized predominantly by $\mathrm{T}$ cell infiltration into the brain consistent with higher levels of $\mathrm{T}$ cell-attracting chemokines (Rempel et al. 2004a, b; Iacono et al. 2006; Scott et al. 2008).

The spike gene has been demonstrated to be a determinant of neurovirulence and to influence macrophage, but not $\mathrm{T}$ cell, infiltration into the brain (Phillips et al. 1999, 2002; Rempel et al. 2004a; Iacono et al. 2006). Analysis of recombinant chimeric A59/JHM viruses was carried out to determine if the spike and/or background genes determined these differences in inflammatory cell infiltrates and chemokine expression. The chimeric rA59/ $\mathrm{S}_{\mathrm{JHM}}$ induces higher CXCL9 (MIG) and CXCL10 (IP-10) expression compared to $\mathrm{rJHM} / \mathrm{S}_{\mathrm{A} 59}$, indicating that the expression of $\mathrm{T}$ cell-attracting chemokines, like the $\mathrm{T}$ cell response itself (see below), is influenced by MHV genes other than spike. In contrast, macrophage chemoattractant expression is elevated during $\mathrm{rA59} / \mathrm{S}_{\mathrm{JHM}}$ infection but not during $\mathrm{rJHM} / \mathrm{S}_{\mathrm{A} 59}$ infection, suggesting an influence by the S gene (Iacono et al. 2006; Rempel et al. 2004a; Scott et al. 2008) consistent with the extensive macrophage infiltration observed in response to viruses expressing the JHM.SD spike. Interestingly, induction of significant levels of neutrophils as well as the neutrophil chemoattractant CXCL2 (MIP-2) required both spike and background genes from JHM.SD (Scott et al. 2008).

$T$ cells in acute disease Numerous studies of MHV infection in immunocompromised severe combined immu- nodeficient (SCID), recombination-activating gene (RAG)deficient, or sublethally irradiated wild-type mice have demonstrated that the host adaptive immune response plays a pivotal role in viral clearance (Wang et al. 1990; Houtman and Fleming 1996; Wu and Perlman 1999; Matthews et al. 2002). Subsequent studies in mice lacking individual lymphocyte populations, either due to antibody depletion or genetic manipulation, combined with reconstitution experiments in mice lacking these lymphocytes have more clearly delineated the roles of CD4 and CD8 T cells in viral control. While both CD4 and CD8 T cells have been shown to be required for effective control of MHV infection in the CNS (Williamson and Stohlman 1990), CD8 T cells are most directly responsible for clearance of infectious virus. Following intracranial inoculation of a sublethal dose of neurotropic MHV, viral titers peak in the brain at day 5 post-infection and then begin to decline, coincident with the accumulation of virus-specific CD8 T cells at the site of infection (Williamson et al. 1991). The importance of CD8 $\mathrm{T}$ cells in the control of MHV is further supported by the increased susceptibility and delayed viral clearance observed in $\beta 2$-microglobulin-deficient mice compared to wild-type control mice (Lavi et al. 1999). Using a model in which C57BL/6 mice were infected with a recombinant A59 virus expressing the GP33 epitope of lymphocytic choriomeningitis virus (LCMV), it was shown that adoptive transfer of naive, GP33-specific CD8 T cells resulted in lower viral titers and reduced antigen distribution in the brain (Chua et al. 2004). Further studies using this adoptive transfer model revealed that increasing the number of naive, virus-specific $\mathrm{CD} 8 \mathrm{~T}$ cells, either before infection or at early times post-infection, reduced viral replication and spread throughout the brain and spinal cord as well as demyelination compared to control mice; thus, enhancing the host CD8 $\mathrm{T}$ cell response was protective against A59induced CNS disease (MacNamara et al. 2005b).

To determine the kinetics of CD8 T cell activation and expansion, BALB/c mice were infected with the glial-tropic JHM variant $2.2-\mathrm{V}-1$ and virus-specific CD8 $\mathrm{T}$ cells were quantified at various times post-infection in the CNS and peripheral lymphoid organs. After intracranial inoculation, virus-specific $\mathrm{CD} 8 \mathrm{~T}$ cells were first detected in the draining cervical lymph nodes (CLN) by day 3 postinfection, followed by further expansion in the spleen and ultimate accumulation in the brain at the initial site of infection, peaking at day 7 post-infection (Marten et al. 2003). These results suggest that the CLN are the initial site of CD8 T cell priming during neurotropic MHV infection. Interestingly, CNS infection with the highly neurovirulent JHM.SD isolate induces a weak antiviral CD8 T cell response in the brain compared to other neurotropic strains (Rempel et al. 2004b; Iacono et al. 2006); infectious virus is not cleared and mice typically succumb to infection by 
day 7 post-infection. This weak CD8 T cell response in the JHM.SD-infected brain has subsequently been shown to correlate with a lack of naive, virus-specific CD8 T cell priming and low levels of viral replication in the draining CLN compared to A59 (MacNamara et al. 2008). Interestingly, studies of recombinant viruses in which the spike genes of A59 and JHM.SD were exchanged reveal that this differential $\mathrm{T}$ cell induction is not due to spike, as replacement of the A59 spike with that of JHM.SD (rA59/ $\mathrm{S}_{\mathrm{JHM}}$ ) resulted in a virus that spreads extensively in the CNS like JHM.SD but induces a robust CD8 $\mathrm{T}$ cell response similar to A59. Furthermore, though $\mathrm{rA59} / \mathrm{S}_{\mathrm{JHM}}$ has an intracranial $\mathrm{LD}_{50}$ similar to JHM.SD, mice infected with $\mathrm{rA59} / \mathrm{S}_{\mathrm{JHM}}$ survive several days longer than those infected with JHM.SD, perhaps due, at least in part, to the effects of antiviral CD8 T cells (Phillips et al. 1999; Iacono et al. 2006). These studies further suggest that even a robust CD8 $T$ cell response may be insufficient to control infection with highly neurovirulent MHV strains.

Activated CD8 $\mathrm{T}$ cells possess numerous effector mechanisms that serve to clear pathogens from infected cells, and the particular mechanisms required for clearance of MHV appear to be specific to the infected cell type. In studies using perforin-deficient mice, clearance of two JHM variants, the moderately virulent JHM-DM isolate (Stohlman et al. 1998) and the neuroattenuated 2.2-V-1 isolate, was delayed compared to wild-type control mice, suggesting that perforin-mediated cytolysis contributes to, but is not required for, clearance of MHV from the CNS; furthermore, JHM-infected perforin-deficient mice still developed encephalomyelitis and demyelination, indicating that these processes are independent of perforin activity (Lin et al. 1997). Interestingly, while CD8 T cell-mediated cytolysis appears to be important for clearance of MHV from astrocytes and microglia (Stohlman et al. 1995), viral clearance from oligodendrocytes instead relies on IFN- $\gamma$ secretion, as indicated by the persistence of the JHM variant $2.2-\mathrm{V}-1$ in oligodendrocytes of IFN- $\gamma$-deficient mice (Parra et al. 1999). Though several neurotropic MHV strains infect large numbers of neurons in addition to glial cells, mechanisms of MHV control in this unique cell type are poorly understood.

While CD8 T cells play a direct role in viral clearance, CD4 T cells are also required for efficient control. In studies using the JHM-DM variant, transfer of activated, virusspecific CD8 T cells into infected wild-type mice resulted in viral clearance, whereas cells transferred into CD4depleted mice were unable to effectively clear virus from the CNS, suggesting that the ability of virus-specific CD8 T cells to control infection depends on CD4 T cells (Stohlman et al. 1998). Furthermore, CD4 T cells have been shown to be required for production of MHV-specific antibodies during infection with the JHM-DS variant (Williamson and
Stohlman 1990). Recent studies in which IFN- $\gamma$ - and perforin-deficient mice were reconstituted with memory CD4 T cells competent in just one of these functions and challenged with the JHM variant $2.2-\mathrm{V}-1$ suggest an additional, more direct role for $\mathrm{CD} 4 \mathrm{~T}$ cells in viral clearance; while viral replication was initially controlled by both IFN- $\gamma$ - and perforin-deficient CD4 T cell populations, only those cells competent to express IFN- $\gamma$ were able to maintain prolonged control (Stohlman et al. 2008). Interestingly, CD4 $\mathrm{T}$ cells have also been shown to play a pathogenic role during MHV infection. Mutation of the immunodominant MHC class II-restricted epitope M133 of the highly neurovirulent JHM.IA strain was shown to prevent mortality in $\mathrm{C} 57 \mathrm{BL} / 6$ mice while having no effect on disease severity in BALB/c mice, a strain in which the M133 epitope is not recognized (Anghelina et al. 2006). Thus, while $\mathrm{T}$ lymphocytes are required for effective clearance of infectious MHV from the CNS, their effects can be both protective and pathogenic to the host.

$T$ cells in chronic disease Following initial clearance of infectious virus, CD8 $\mathrm{T}$ cells in the CNS decrease in number but are not eliminated. Furthermore, while infectious virus is reduced to undetectable levels, viral RNA may persist in the CNS for the life of the mouse. A study comparing two glial-tropic JHM variants, one that persists and one that is cleared, showed that maintenance of CD4 and CD8 T cells within the infected CNS correlated with the continued presence of viral RNA, suggesting that viral persistence (as evidenced by detection of viral RNA) provides a signal that is necessary to maintain these lymphocyte populations within the CNS (Marten et al. 2000a). Further studies using the glial-tropic JHM variant 2.2-V-1 revealed that CD8 T cells maintained in the CNS after viral clearance displayed a loss of ex vivo cytolytic activity while maintaining the ability to secrete IFN- $\gamma$ (Bergmann et al. 1999). Recent studies revealed that CD8 T cells maintain expression of programmed death 1 (PD-1) during persistence of the JHM variant $2.2-\mathrm{V}-1$ in the CNS, while expression of the PD-1 ligand B7-H1 is concurrently maintained on oligodendrocytes; the authors suggest that this PD-1/B7-H1 interaction contributes to CD8 $\mathrm{T}$ cell dysfunction during persistence (Phares et al. 2009). Interestingly, recent studies by Zhao et al. have extended these findings, using adoptive transfer techniques and bone marrow chimeras to demonstrate that antiviral CD8 $\mathrm{T}$ cell populations are maintained during persistence in the CNS, at least in part, by recruitment of both antigen-experienced and naive $\mathrm{CD} 8 \mathrm{~T}$ cells from the periphery (Zhao et al. 2009).

It remains unclear whether CD8 $\mathrm{T}$ cells present in the CNS during persistence of neurotropic MHV strains prevent reactivation of virus, contribute to CNS pathology, 
or participate in both protection and disease. Whether these CD8 T cells are more protective and memory-like or instead show signs of exhaustion is an area of ongoing research. However, preliminary studies using a recombinant A59 virus expressing the GP33 epitope of LCMV suggest that the virus-specific CD8 $\mathrm{T}$ cells maintained in the CNS during persistent infection are intermediate in phenotype and function compared to protective memory cells generated after clearance of the LCMV Armstrong strain and exhausted CD8 $\mathrm{T}$ cells present during chronic infection with the LCMV clone-13 strain, perhaps due to ongoing viral antigen expression and/or inflammation during MHV persistence (Bender et al., manuscript in preparation). It will be interesting to compare the CD8 $\mathrm{T}$ cells present during persistent infection with glial-tropic strains to those present during infection with MHV strains that infect neurons in addition to glia.

Another phenomenon described during persistent MHV infection is that of epitope escape. Using the suckling mouse model of JHM infection in which suckling mice are nursed by immunized dams to protect from acute encephalitic disease, viral RNA was sequenced from the brains of JHM-infected mice at numerous times post-infection to determine the integrity of the immunodominant $\mathrm{H}-2 \mathrm{D}^{\mathrm{b}}$ restricted S510 epitope. Interestingly, mutations in this epitope were detected beginning as early as day 10 postinfection in wild-type mice with hindlimb paralysis but not in persistently infected SCID mice, suggesting that epitope escape occurs only in the presence of immune pressure (Pewe et al. 1997). Subsequent studies showed that increased levels of MHV-specific antibody in the CNS reduced the emergence of MHC class I-restricted epitope escape mutants by preventing the onset of chronic disease in the suckling mouse model (Dandekar et al. 2003). Studies using B celldeficient mice further support a role for antibody in preventing epitope escape (Butler et al. 2007). The S510 epitope escape mutants isolated from persistently infected suckling mice displayed increased morbidity and mortality compared to parental JHM upon infection of naive suckling mice, suggesting that the escape from the response to S510 is a determinant of virulence and disease (Pewe et al. 1998). Interestingly, in contrast to suckling mice, similar epitope escape mutants were slightly attenuated when used to infect weanling mice. Furthermore, the effect of epitope escape mutations on pathogenesis depended on both viral background genes other than the spike and the mouse strain infected (MacNamara et al. 2005a). Thus, epitope escape is unlikely to be a general mechanism that contributes significantly to MHV persistence.

$B$ cells and antibody In addition to virus-specific $\mathrm{T}$ cells, antiviral antibody is also known to play a protective role against MHV infection. Passive transfer of monoclonal antibodies specific for individual viral proteins has been shown to protect against lethal MHV infection, though evidence of sublethal infection and demyelination was still detected (Buchmeier et al. 1984; Wege et al. 1984; Nakanaga et al. 1986). Furthermore, infection of muMT mice with A59 showed that infectious virus was not cleared from the CNS in the absence of mature B cells, and passive transfer of A59-specific antibody into infected muMT mice subsequently decreased viral load, further supporting a role for B cells and antibody in control of MHV in the CNS. Interestingly, clearance of A59 from the livers of these mice did not require B cells (Matthews et al. 2001).

In other studies, infection of IgM-deficient mice with the JHM variant 2.2-V-1 revealed initial control of infectious virus during acute infection but subsequent viral reactivation at later times compared to wild-type mice; administration of MHV-specific antibody after initial viral control suppressed this viral recrudescence (Lin et al. 1999). Interestingly, reactivation of virus in antibody-deficient mice was reported primarily in oligodendrocytes, while viral recrudescence in B cell-deficient mice was observed in both oligodendrocytes and astrocytes, suggesting an additional level of protection provided by $\mathrm{B}$ cells during persistence (Ramakrishna et al. 2002). Furthermore, the numbers of antibody-secreting cells were shown to remain stable during persistence (Tschen et al. 2002). Taken together, it is likely that $\mathrm{T}$ cell-mediated cytolysis, cytokine secretion, and antibody production play a collective role in clearing infectious virus and subsequently maintaining control of MHV during persistence in the CNS.

\section{Demyelination}

MHV infection of the CNS is one of the recognized animal models for studying the human demyelinating disease multiple sclerosis. As described above, infectious virus is largely cleared from the adult CNS by about 7-10 days post-infection. In animals surviving the acute infection, viral RNA persists for the lifetime of the mouse, accompanied by virus-specific $T$ cells. These surviving mice later develop demyelination, as evidenced by clinical signs such as hindlimb weakness, awkward gait, and ultimately paralysis. Demyelinated lesions, such as those resulting from A59 infection, are usually assessed by staining of spinal cord sections with Luxol Fast Blue and are maximal at 1 month post-infection (Lavi et al. 1984b; Das Sarma et al. 2000; Matthews et al. 2002; MacNamara et al. 2005a).

MHV strain is important in determining the extent and intensity of late demyelinating disease. Strains such as JHM.SD or JHM-DL are so highly neurovirulent that most infected animals die from acute encephalitis, leaving few survivors with which to study the late demyelinating 
disease (Stohlman et al. 1982; Ontiveros et al. 2003). Thus, studies of MHV-induced demyelination have utilized either neuroattenuated variants of JHM, such as 2.2-V-1 (Fleming et al. 1986; Marten et al. 2000b), the less neurovirulent A59 strain (Lavi et al. 1984b; MacNamara et al. 2005a), or infection of passively immunized suckling mice (Pewe et al. 1996). The use of these models ensures enough survivors of acute infection to allow the study of demyelination. With the exception of the suckling mouse model (Pewe et al. 1999), demyelination occurs in the absence of detectable infectious virus. This result is in contrast to the Theiler's virus-induced demyelination mouse model, in which there is persistence of infectious virus (Stohlman and Hinton 2001).

Early studies of MHV-induced demyelination suggested that demyelination was mediated directly by infection due to cytopathic effects of the virus on oligodendrocytes (Lampert et al. 1973; Weiner 1973). While the mechanism of MHV-induced demyelination is still not well understood, it is clear that immune-mediated damage is the major mechanism of the demyelination process. The immune response plays a dual role in demyelination by both modulating the amount of virus that spreads into the spinal cord and participating more directly in loss of myelin. The extent of viral spread during acute infection is an important predictor of the development of late demyelination (Marten et al. 2000b; MacNamara et al. 2005b) and is determined by the inherent ability of the virus strain to spread among CNS cell types balanced by the ability of the host to clear virus, which is largely determined by the CD8 T cell response. Understanding the contributions of the immune response to the pathology of demyelination is an active area of MHV research. It is likely that the demyelinating process involves multiple cell types and cytokines, some of which may play redundant roles.

MHV-induced demyelination is characterized by inflammatory infiltrates consisting of lymphocytes and lipidcontaining macrophages (Stohlman and Weiner 1981; Lavi et al. 1986a, b; Wu and Perlman 1999). Using infections with the attenuated JHM 2.2-V-1 variant, it was recently demonstrated that both monocyte-derived macrophages and microglia are present in regions of demyelination and can be seen in contact with demyelinated axons, suggesting that both cell types participate in the demyelinating process (Templeton et al. 2008). The JHM-infected RAG-deficient mouse model, developed by Stanley Perlman and colleagues, has also been useful in dissecting the factors necessary for immune-mediated demyelination. Infected RAG-deficient mice do not develop demyelination; however, adoptive transfer of splenocytes from infected immunocompetent mice into RAG-deficient mice restores demyelination, which is associated with extensive recruitment of activated macrophages and microglia to the sites of spinal cord demyelination (Wang et al. 1990; Wu and Perlman 1999). Furthermore, transfer of either CD4 or CD8 $\mathrm{T}$ cells also restores the development of demyelination in RAG-deficient mice, perhaps by triggering astrocytes to produce chemokines (Lane et al. 1998). Thus, while either CD4 or CD8 T cells are sufficient to promote demyelination, neither cell type is essential (Wu et al. 2000; Matthews et al. 2002). Infection of B cell-deficient mice similarly confirmed that this cell type is also not required for the development of demyelination (Matthews et al. 2002).

The persistence of viral RNA, both genome and mRNA (unpublished data), and likely low levels of viral antigen within the CNS are responsible for the maintenance of $\mathrm{T}$ cells in the CNS during chronic disease (Ramakrishna et al. 2004, 2006). Furthermore, expression of CXCL10 (IP-10) and CCL5 (RANTES), which attract T cells and macrophages respectively, remains elevated during late disease, and the observation that antibody depletion of either CXCL10 or CCL5 results in reduced levels of demyelination suggests an important role for these chemokines (Liu et al. 2001; Glass et al. 2002, 2004). Chronic activation of astrocytes during persistent infection contributes to demyelination via the secretion of macrophage and $T$ cell chemoattractants, and it has been suggested that additional secretion of TNF- $\alpha$, IL-1 $\beta$, IL- 6 , and type 2 nitric oxide synthesis (iNOS) by astrocytes may directly contribute to the dysregulation of oligodendrocyte function and resulting myelin loss (Sun et al. 1995; Grzybicki et al. 1997).

\section{Discussion}

Despite numerous advances in our understanding of coronavirus pathogenesis, many questions remain. It is unclear how neurotropic strains of MHV infect and spread in CNS cell types expressing low to nonexistent levels of the receptor CEACAM1a and how strains using the same cellular receptor can exhibit such varied cellular tropisms. It will be important to understand how MHV infection of individual CNS cell types is recognized and subsequently cleared by the host, as well as how the virus is able to establish persistence. The diversity of neurotropic strains combined with the relative ease of genetic manipulation makes MHV an important tool for elucidating viral and host factors involved in CNS disease.

\section{References}

An S, Chen CJ, Yu X, Leibowitz JL, Makino S (1999) Induction of apoptosis in murine coronavirus-infected cultured cells and demonstration of $\mathrm{E}$ protein as an apoptosis inducer. J Virol 73:7853-7859 
Anghelina D, Pewe L, Perlman S (2006) Pathogenic role for virusspecific CD4 $\mathrm{T}$ cells in mice with coronavirus-induced acute encephalitis. Am J Pathol 169:209-222

Bailey OT, Pappenheimer AM, Sargent F, Cheever MD, Daniels JB (1949) A murine virus (JHM) causing disseminated encephalomyelitis with extensive destruction of myelin. II. Pathology. J Exp Med 90:195-212

Barretto N, Jukneliene D, Ratia K, Chen Z, Mesecar AD, Baker SC (2005) The papain-like protease of severe acute respiratory syndrome coronavirus has deubiquitinating activity. J Virol 79:15189-15198

Bergmann CC, Altman JD, Hinton D, Stohlman SA (1999) Inverted immunodominance and impaired cytolytic function of CD8+ T cells during viral persistence in the central nervous system. J Immunol 163:3379-3387

Bergmann CC, Lane TE, Stohlman SA (2006) Coronavirus infection of the central nervous system: host-virus stand-off. Nat Rev Microbiol 4:121-132

Buchmeier MJ, Lewicki HA, Talbot PJ, Knobler RL (1984) Murine hepatitis virus-4 (strain JHM)-induced neurologic disease is modulated in vivo by monoclonal antibody. Virology 132:261270

Butler NS, Dandekar AA, Perlman S (2007) Antiviral antibodies are necessary to prevent cytotoxic T-lymphocyte escape in mice infected with a coronavirus. J Virol 81:13291-13298

Cervantes-Barragan L, Zust R, Weber F, Spiegel M, Lang KS, Akira S, Thiel V, Ludewig B (2007) Control of coronavirus infection through plasmacytoid dendritic-cell-derived type I interferon. Blood 109:1131-1137

Cervantes-Barragan L, Kalinke U, Zust R, Konig M, Reizis B, LopezMacias C, Thiel V, Ludewig B (2009) Type I IFN-mediated protection of macrophages and dendritic cells secures control of murine coronavirus infection. J Immunol 182:1099-1106

Changolkar LN, Singh G, Pehrson JR (2008) macroH2A1-dependent silencing of endogenous murine leukemia viruses. Mol Cell Biol 28:2059-2065

Cheever FS, Daniels JB, Pappenheimer AM, Baily OT (1949) A murine virus (JHM) causing disseminated encephalomyelitis with extensive destruction of myelin. I. Isolation and biological properties of the virus. J Exp Med 90:181-194

Chen DS, Asanaka M, Yokomori K, Wang F, Hwang SB, Li HP, Lai MM (1995) A pregnancy-specific glycoprotein is expressed in the brain and serves as a receptor for mouse hepatitis virus. Proc Natl Acad Sci U S A 92:12095-12099

Chen Z, Chen L, Qiao SW, Nagaishi T, Blumberg RS (2008) Carcinoembryonic antigen-related cell adhesion molecule 1 inhibits proximal TCR signaling by targeting ZAP-70. J Immunol 180:6085-6093

Chiu SS, Chan KH, Chu KW, Kwan SW, Guan Y, Poon LL, Peiris JS (2005) Human coronavirus NL63 infection and other coronavirus infections in children hospitalized with acute respiratory disease in Hong Kong, China. Clin Infect Dis 40:1721-1729

Chua MM, MacNamara KC, San Mateo L, Shen H, Weiss SR (2004) Effects of an epitope-specific CD8+ T-cell response on murine coronavirus central nervous system disease: protection from virus replication and antigen spread and selection of epitope escape mutants. J Virol 78:1150-1159

Compton SR, Rogers DB, Holmes KV, Fertsch D, Remenick J, McGowan JJ (1987) In vitro replication of mouse hepatitis virus strain A59. J Virol 61:1814-1820

Coutelier JP, Godfraind C, Dveksler GS, Wysocka M, Cardellichio CB, Noel H, Holmes KV (1994) B lymphocyte and macrophage expression of carcinoembryonic antigen-related adhesion molecules that serve as receptors for murine coronavirus. Eur $\mathrm{J}$ Immunol 24:1383-1390
Cowley TJ, Long SY, Weiss SR (2010) The murine coronavirus nucleocapsid gene is a determinant of virulence. J Virol 84 (4): $1752-1763$

Dalziel RG, Lampert PW, Talbot PJ, Buchmeier MJ (1986) Sitespecific alteration of murine hepatitis virus type 4 peplomer glycoprotein E2 results in reduced neurovirulence. J Virol 59:463-471

Dandekar AA, Jacobsen G, Waldschmidt TJ, Perlman S (2003) Antibody-mediated protection against cytotoxic T-cell escape in coronavirus-induced demyelination. J Virol 77:11867-11874

Das Sarma J, Fu L, Tsai JC, Weiss SR, Lavi E (2000) Demyelination determinants map to the spike glycoprotein gene of coronavirus mouse hepatitis virus. J Virol 74:9206-9213

de Haan CA, de Wit M, Kuo L, Montalto-Morrison C, Haagmans BL, Weiss SR, Masters PS, Rottier PJ (2003) The glycosylation status of the murine hepatitis coronavirus $M$ protein affects the interferogenic capacity of the virus in vitro and its ability to replicate in the liver but not the brain. Virology 312:395-406

de Haan CA, Rottier PJ (2005) Molecular interactions in the assembly of coronaviruses. Adv Virus Res 64:165-230

Detje CN, Meyer T, Schmidt H, Kreuz D, Rose JK, Bechmann I, Prinz M, Kalinke U (2009) Local type I IFN receptor signaling protects against virus spread within the central nervous system. J Immunol 182:2297-2304

Devaraj SG, Wang N, Chen Z, Chen Z, Tseng M, Barretto N, Lin R, Peters CJ, Tseng CT, Baker SC, Li K (2007) Regulation of IRF3 -dependent innate immunity by the papain-like protease domain of the severe acute respiratory syndrome coronavirus. J Biol Chem 282:32208-32221

Drosten C, Gunther S, Preiser W, van der Werf S, Brodt HR, Becker S, Rabenau H, Panning M, Kolesnikova L, Fouchier RA, Berger A, Burguiere AM, Cinatl J, Eickmann M, Escriou N, Grywna K, Kramme S, Manuguerra JC, Muller S, Rickerts V, Sturmer M, Vieth S, Klenk HD, Osterhaus AD, Schmitz H, Doerr HW (2003) Identification of a novel coronavirus in patients with severe acute respiratory syndrome. N Engl J Med 348:1967-1976

Dveksler GS, Pensiero MN, Dieffenbach CW, Cardellichio CB, Basile AA, Elia PE, Holmes KV (1993a) Mouse hepatitis virus strain A59 and blocking antireceptor monoclonal antibody bind to the N-terminal domain of cellular receptor. Proc Natl Acad Sci U S A 90:1716-1720

Dveksler GS, Dieffenbach CW, Cardellichio CB, McCuaig K, Pensiero MN, Jiang GS, Beauchemin N, Holmes KV (1993b) Several members of the mouse carcinoembryonic antigen-related glycoprotein family are functional receptors for the coronavirus mouse hepatitis virus-A59. J Virol 67:1-8

Eckerle LD, Lu X, Sperry SM, Choi L, Denison MR (2007) High fidelity of murine hepatitis virus replication is decreased in nsp14 exoribonuclease mutants. J Virol 81:12135-12144

Egloff MP, Malet H, Putics A, Heinonen M, Dutartre H, Frangeul A, Gruez A, Campanacci V, Cambillau C, Ziebuhr J, Ahola T, Canard B (2006) Structural and functional basis for ADP-ribose and poly(ADP-ribose) binding by viral macro domains. J Virol 80:8493-8502

Fazakerley JK, Parker SE, Bloom F, Buchmeier MJ (1992) The V5A13.1 envelope glycoprotein deletion mutant of mouse hepatitis virus type- 4 is neuroattenuated by its reduced rate of spread in the central nervous system. Virol 187:178-188

Fleming JO, Trousdale MD, El-Zaatari FAK, Stohlman SA, Weiner LP (1986) Pathogenicity of antigenic variants of murine coronavirus JHM seleced with monoclonal antibodies. J Virol 58:869-875

Frana MF, Behnke JN, Sturman LS, Holmes KV (1985) Proteolytic cleavage of the E2 glycoprotein of murine coronavirus: hostdependent differences in proteolytic cleavage and cell fusion. $\mathrm{J}$ Virol 56:912-920 
Frieman M, Heise M, Baric R (2008) SARS coronavirus and innate immunity. Virus Res 133:101-112

Frieman M, Ratia K, Johnston RE, Mesecar AD, Baric RS (2009) Severe acute respiratory syndrome coronavirus papain-like protease ubiquitin-like domain and catalytic domain regulate antagonism of IRF3 and NF-kappaB signaling. J Virol 83:66896705

Gallagher TM, Parker SE, Buchmeier MJ (1990) Neutralizationresistant variants of a neurotropic coronavirus are generated by deletions within the amino-terminal half of the spike glycoprotein. J Virol 64:731-741

Gallagher TM, Escarmis C, Buchmeier MJ (1991) Alteration of the $\mathrm{pH}$ dependence of coronavirus-induced cell fusion: effect of mutations in the spike glycoprotein. J Virol 65:1916-1928

Gallagher TM, Buchmeier MJ, Perlman S (1992) Cell receptorindependent infection by a neurotropic murine coronavirus. Virology 191:517-522

Gallagher TM, Buchmeier MJ (2001) Coronavirus spike proteins in viral entry and pathogenesis. Virology 279:371-374

Glass WG, Chen BP, Liu MT, Lane TE (2002) Mouse hepatitis virus infection of the central nervous system: chemokine-mediated regulation of host defense and disease. Viral Immunol 15:261272

Glass WG, Hickey MJ, Hardison JL, Liu MT, Manning JE, Lane TE (2004) Antibody targeting of the CC chemokine ligand 5 results in diminished leukocyte infiltration into the central nervous system and reduced neurologic disease in a viral model of multiple sclerosis. J Immunol 172:4018-4025

Godfraind C, Langreth SG, Cardellichio CB, Knobler R, Coutelier JP, Dubois-Dalcq M, Holmes KV (1995) Tissue and cellular distribution of an adhesion molecule in the carcinoembryonic antigen family that serves as a receptor for mouse hepatitis virus. Lab Invest 73:615-627

Godfraind C, Havaux N, Holmes KV, Coutelier JP (1997) Role of virus receptor-bearing endothelial cells of the blood-brain barrier in preventing the spread of mouse hepatitis virus-A59 into the central nervous system. J Neurovirology 3:428-434

Gorbalenya AE, Koonin EV, Lai MM (1991) Putative papain-related thiol proteases of positive-strand RNA viruses. Identification of rubi- and aphthovirus proteases and delineation of a novel conserved domain associated with proteases of rubi-, alpha- and coronaviruses. FEBS Lett 288:201-205

Gorbalenya AE, Enjuanes L, Ziebuhr J, Snijder EJ (2006) Nidovirales: evolving the largest RNA virus genome. Virus Res 117:17-37

Gray-Owen SD, Blumberg RS (2006) CEACAM1: contact-dependent control of immunity. Nat Rev Immunol 6:433-446

Grossoehme NE, Li L, Keane SC, Liu P, Dann CE 3rd, Leibowitz JL, Giedroc DP (2009) Coronavirus N protein N-terminal domain (NTD) specifically binds the transcriptional regulatory sequence (TRS) and melts TRS-cTRS RNA duplexes. J Mol Biol 394:544 557

Grzybicki DM, Kwack KB, Perlman S, Murphy SP (1997) Nitric oxide synthase type II expression by different cell types in MHV-JHM encephalitis suggests distinct roles for nitric oxide in acute versus persistent virus infection. J Neuroimmunol 73: $15-27$

Hamre D, Procknow JJ (1966) A new virus isolated from the human respiratory tract. Proc Soc Exp Biol Med 121:190-193

Hemmila E, Turbide C, Olson M, Jothy S, Holmes KV, Beauchemin N (2004) Ceacam1a-/- mice are completely resistant to infection by murine coronavirus mouse hepatitis virus A59. J Virol 78:10156-10165

Homberger FR, Zhang L, Barthold SW (1998) Prevalence of enterotropic and polytropic mouse hepatitis virus in enzootically infected mouse colonies. Lab Anim Sci 48:50-54
Houtman JJ, Fleming JO (1996) Dissociation of demyelination and viral clearance in congenitally immunodeficient mice infected with murine coronavirus JHM. J Neurovirology 2:101-110

Hurst KR, Kuo L, Koetzner CA, Ye R, Hsue B, Masters PS (2005) A major determinant for membrane protein interaction localizes to the carboxy-terminal domain of the mouse coronavirus nucleocapsid protein. J Virol 79:13285-13297

Iacono KT, Kazi L, Weiss SR (2006) Both spike and background genes contribute to murine coronavirus neurovirulence. J Virol 80:6834-6843

Ireland DD, Stohlman SA, Hinton DR, Atkinson R, Bergmann CC (2008) Type I interferons are essential in controlling neurotropic coronavirus infection irrespective of functional CD8 T cells. J Virol 82:300-310

Kammerer R, Stober D, Singer BB, Obrink B, Reimann J (2001) Carcinoembryonic antigen-related cell adhesion molecule 1 on murine dendritic cells is a potent regulator of $\mathrm{T}$ cell stimulation. $\mathrm{J}$ Immunol 166:6537-6544

Kazi L, Lissenberg A, Watson R, de Groot RJ, Weiss SR (2005) Expression of hemagglutinin esterase protein from recombinant mouse hepatitis virus enhances neurovirulence. J Virol 79:15064-15073

Kienzle TE, Abraham S, Hogue BG, Brian DA (1990) Structure and orientation of expressed bovine coronavirus hemagglutininesterase protein. J Virol 64:1834-1838

Koetzner CA, Parker MM, Ricard CS, Sturman LS, Masters PS (1992) Repair and mutagenesis of the genome of a deletion mutant of the coronavirus mouse hepatitis virus by targeted RNA recombination. J Virol 66:1841-1848

Kooi C, Cervin M, Anderson R (1991) Differentiation of acid-pHdependent and -nondependent entry pathways for mouse hepatitis virus. Virology 180:108-119

Krueger DK, Kelly SM, Lewicki DN, Ruffolo R, Gallagher TM (2001) Variations in disparate regions of the murine coronavirus spike protein impact the initiation of membrane fusion. J Virol 75:2792-2802

Ksiazek TG, Erdman D, Goldsmith CS, Zaki SR, Peret T, Emery S, Tong S, Urbani C, Comer JA, Lim W, Rollin PE, Dowell SF, Ling AE, Humphrey CD, Shieh WJ, Guarner J, Paddock CD, Rota P, Fields B, DeRisi J, Yang JY, Cox N, Hughes JM, LeDuc JW, Bellini WJ, Anderson LJ (2003) A novel coronavirus associated with severe acute respiratory syndrome. N Engl J Med 348:1953-1966

Kuespert K, Pils S, Hauck CR (2006) CEACAMs: their role in physiology and pathophysiology. Curr Opin Cell Biol 18:565571

Kuo L, Godeke GJ, Raamsman MJ, Masters PS, Rottier PJ (2000) Retargeting of coronavirus by substitution of the spike glycoprotein ectodomain: crossing the host cell species barrier. J Virol 74:1393-1406

Kuo L, Masters PS (2003) The small envelope protein E is not essential for murine coronavirus replication. J Virol 77:45974608

Lai MM, Stohlman SA (1978) RNA of mouse hepatitis virus. J Virol $26: 236-242$

LaMonica N, Banner LR, Morris VL, Lai MMC (1991) Localization of extensive deletions in the structural genes of two neurotropic variants of murine coronavirus JHM. Virology 182:883-888

Lampert PW, Sims JK, Kniazeff AJ (1973) Mechanism of demyelination in JHM virus encephalomyelitis. Acta Neurophathol 24:7685

Lane TE, Asensio VC, Yu N, Paoletti AD, Campbell IL, Buchmeier MJ (1998) Dynamic regulation of alpha- and beta-chemokine expression in the central nervous system during mouse hepatitis virus-induced demyelinating disease. J Immunol 160:970-978 
Laude H, Gelfi J, Lavenant L, Charley B (1992) Single amino acid changes in the viral glycoprotein $\mathrm{M}$ affect induction of alpha interferon by the coronavirus transmissible gastroenteritis virus. J Virol 66:743-749

Lavi E, Gilden DH, Highkin MK, Weiss SR (1984a) Persistence of mouse hepatitis virus A59 RNA in a slow virus demyelinating infection in mice as detected by in situ hybridization. J Virol 51:563-566

Lavi E, Gilden DH, Wroblewska Z, Rorke LB, Weiss SR (1984b) Experimental demyelination produced by the A59 strain of mouse hepatitis virus. Neurology 34:597-603

Lavi E, Gilden DH, Highkin MK, Weiss SR (1986a) The organ tropism of mouse hepatitis virus A59 in mice is dependent on dose and route of inoculation. Lab Anim Sci 36:130-135

Lavi E, Fishman PS, Highkin MK, Weiss SR (1986b) Neurology 36 (suppl 1):221

Lavi E, Das Sarma J, Weiss SR (1999) Cellular reservoirs for coronavirus infection of the brain in beta2-microglobulin knockout mice. Pathobiology 67:75-83

Lee HJ, Shieh CK, Gorbalenya AE, Koonin EV, La Monica N, Tuler J, Bagdzhadzhyan A, Lai MM (1991) The complete sequence (22 kilobases) of murine coronavirus gene 1 encoding the putative proteases and RNA polymerase. Virology 180:567-582

Leparc-Goffart I, Hingley ST, Chua MM, Jiang X, Lavi E, Weiss SR (1997) Altered pathogenesis of a mutant of the murine coronavirus MHV-A59 is associated with a Q159L amino acid substitution in the spike protein. Virology 239:1-10

Leparc-Goffart I, Hingley ST, Chua MM, Phillips J, Lavi E, Weiss SR (1998) Targeted recombination within the spike gene of murine coronavirus mouse hepatitis virus-A59: Q159 is a determinant of hepatotropism. J Virol 72:9628-9636

Lin MT, Stohlman SA, Hinton DR (1997) Mouse hepatitis virus is cleared from the central nervous systems of mice lacking perforin-mediated cytolysis. J Virol 71:383-391

Lin MT, Hinton DR, Marten NW, Bergmann CC, Stohlman SA (1999) Antibody prevents virus reactivation within the central nervous system. J Immunol 162:7358-7368

Liu MT, Keirstead HS, Lane TE (2001) Neutralization of the chemokine CXCL10 reduces inflammatory cell invasion and demyelination and improves neurological function in a viral model of multiple sclerosis. J Immunol 167:4091-4097

Luytjes W, Bredenbeek PJ, Noten AF, Horzinek MC, Spaan WJ (1988) Sequence of mouse hepatitis virus A59 mRNA 2: indications for RNA recombination between coronaviruses and influenza C virus. Virology 166:415-422

MacNamara KC, Chua MM, Phillips JJ, Weiss SR (2005a) Contributions of the viral genetic background and a single amino acid substitution in an immunodominant CD8+ T-cell epitope to murine coronavirus neurovirulence. J Virol 79:9108-9118

MacNamara KC, Chua MM, Nelson PT, Shen H, Weiss SR (2005b) Increased epitope-specific CD8+ T cells prevent murine coronavirus spread to the spinal cord and subsequent demyelination. $\mathrm{J}$ Virol 79:3370-3381

MacNamara KC, Bender SJ, Chua MM, Watson R, Weiss SR (2008) Priming of CD8 $+\mathrm{T}$ cells during central nervous system infection with a murine coronavirus is strain dependent. J Virol 82:6150 6160

Manaker RA, Piczak CV, Miller AA, Stanton MF (1961) A hepatitis virus complicating studies with mouse leukemia. J Natl Cancer Inst 27:29-51

Marten NW, Stohlman SA, Bergmann CC (2000a) Role of viral persistence in retaining $\mathrm{CD} 8(+) \mathrm{T}$ cells within the central nervous system. J Virol 74:7903-7910

Marten NW, Stohlman SA, Atkinson RD, Hinton DR, Fleming JO, Bergmann CC (2000b) Contributions of CD8+ T cells and viral spread to demyelinating disease. J Immunol 164:4080-4088
Marten NW, Stohlman SA, Bergmann CC (2001) MHV infection of the CNS: mechanisms of immune-mediated control. Viral Immunol 14(1):1-18

Marten NW, Stohlman SA, Zhou J, Bergmann CC (2003) Kinetics of virus-specific CD8+-T-cell expansion and trafficking following central nervous system infection. J Virol 77:2775-2778

Matsuyama S, Watanabe R, Taguchi F (2001) Neurovirulence in mice of soluble receptor-resistant (srr) mutants of mouse hepatitis virus: intensive apoptosis caused by less virulent srr mutant. Arch Virol 146:1643-1654

Matsuyama S, Taguchi F (2002a) Communication between S1N330 and a region in $\mathrm{S} 2$ of murine coronavirus spike protein is important for virus entry into cells expressing CEACAM1b receptor. Virology 295:160-171

Matsuyama S, Taguchi F (2002b) Receptor-induced conformational changes of murine coronavirus spike protein. J Virol 76:1181911826

Matthews AE, Weiss SR, Shlomchik MJ, Hannum LG, Gombold JL, Paterson Y (2001) Antibody is required for clearance of infectious murine hepatitis virus A59 from the central nervous system, but not the liver. J Immunol 167:5254-5263

Matthews AE, Lavi E, Weiss SR, Paterson Y (2002) Neither B cells nor $\mathrm{T}$ cells are required for CNS demyelination in mice persistently infected with MHV-A59. J Neurovirology 8:257-264

McCuaig K, Turbide C, Beauchemin N (1992) mmCGM1a: a mouse carcinoembryonic antigen gene family member, generated by alternative splicing, functions as an adhesion molecule. Cell Growth Differ 3:165-174

McCuaig K, Rosenberg M, Nedellec P, Turbide C, Beauchemin N (1993) Expression of the Bgp gene and characterization of mouse colon biliary glycoprotein isoforms. Gene 127:173-183

McIntosh K, Dees JH, Becker WB, Kapikian AZ, Chanock RM (1967) Recovery in tracheal organ cultures of novel viruses from patients with respiratory disease. Proc Natl Acad Sci U S A 57:933-940

Miura TA, Travanty EA, Oko L, Bielefeldt-Ohmann H, Weiss SR, Beauchemin N, Holmes KV (2008) The spike glycoprotein of murine coronavirus MHV-JHM mediates receptor-independent infection and spread in the central nervous systems of Ceacam1a -/- mice. J Virol 82:755-763

Nakagaki K, Taguchi F (2005) Receptor-independent spread of a highly neurotropic murine coronavirus JHMV strain from initially infected microglial cells in mixed neural cultures. J Virol 79:6102-6110

Nakajima A, Iijima H, Neurath MF, Nagaishi T, Nieuwenhuis EE, Raychowdhury R, Glickman J, Blau DM, Russell S, Holmes KV, Blumberg RS (2002) Activation-induced expression of carcinoembryonic antigen-cell adhesion molecule 1 regulates mouse $\mathrm{T}$ lymphocyte function. J Immunol 168:1028-1035

Nakanaga K, Yamanouchi K, Fujiwara K (1986) Protective effect of monoclonal antibodies on lethal mouse hepatitis virus infection in mice. J Virol 59:168-171

Narayanan K, Huang C, Lokugamage K, Kamitani W, Ikegami T, Tseng CT, Makino S (2008) Severe acute respiratory syndrome coronavirus nsp1 suppresses host gene expression, including that of type I interferon, in infected cells. J Virol 82:4471-4479

Nash TC, Buchmeier MJ (1997) Entry of mouse hepatitis virus into cells by endosomal and nonendosomal pathways. Virology 233:1-8

Navas S, Weiss SR (2003) Murine coronavirus-induced hepatitis: JHM genetic background eliminates A59 spike-determined hepatotropism. J Virol 77:4972-4978

Nedellec P, Dveksler GS, Daniels E, Turbide C, Chow B, Basile AA, Holmes KV, Beauchemin N (1994) Bgp2, a new member of the carcinoembryonic antigen-related gene family, encodes an alternative receptor for mouse hepatitis viruses. J Virol 68:4525-4537 
Ning Q, Liu M, Kongkham P, Lai MM, Marsden PA, Tseng J, Pereira B, Belyavskyi M, Leibowitz J, Phillips MJ, Levy G (1999) The nucleocapsid protein of murine hepatitis virus type 3 induces transcription of the novel fgl2 prothrombinase gene. J Biol Chem 274:9930-9936

Ning Q, Sun Y, Han M, Zhang L, Zhu C, Zhang W, Guo H, Li J, Yan W, Gong F, Chen Z, He W, Koscik C, Smith R, Gorczynski R, Levy G, Luo X (2005) Role of fibrinogen-like protein 2 prothrombinase/fibroleukin in experimental and human allograft rejection. J Immunol 174:7403-7411

Ontiveros E, Kim TS, Gallagher TM, Perlman S (2003) Enhanced virulence mediated by the murine coronavirus, mouse hepatitis virus strain JHM, is associated with a glycine at residue 310 of the spike glycoprotein. J Virol 77:10260-10269

Osterhaus AD, Fouchier RA, Kuiken T (2004) The aetiology of SARS: Koch's postulates fulfilled. Philos Trans R Soc Lond B Biol Sci 359:1081-1082

Park E, Griffin DE (2009a) Interaction of Sindbis virus non-structural protein 3 with poly(ADP-ribose) polymerase 1 in neuronal cells. J Gen Virol 90:2073-2080

Park E, Griffin DE (2009b) The nsP3 macro domain is important for Sindbis virus replication in neurons and neurovirulence in mice. Virology 388:305-314

Parr RL, Fung L, Reneker J, Myers-Mason N, Leibowitz JL, Levy G (1995) Association of mouse fibrinogen-like protein with murine hepatitis virus-induced prothrombinase activity. J Virol 69:50335038

Parra B, Hinton DR, Marten NW, Bergmann CC, Lin MT, Yang CS, Stohlman SA (1999) IFN-gamma is required for viral clearance from central nervous system oligodendroglia. J Immunol 162:1641-1647

Pasick JM, Kalicharran K, Dales S (1994) Distribution and trafficking of JHM coronavirus structural proteins and virions in primary neurons and the OBL-21 neuronal cell line. J Virol 68:29152928

Pearce BD, Hobbs MV, McGraw TS, Buchmeier MJ (1994) Cytokine induction during T-cell-mediated clearance of mouse hepatitis virus from neurons in vivo. J Virol 68:5483-5495

Peiris JS, Lai ST, Poon LL, Guan Y, Yam LY, Lim W, Nicholls J, Yee WK, Yan WW, Cheung MT, Cheng VC, Chan KH, Tsang DN, Yung RW, Ng TK, Yuen KY (2003) Coronavirus as a possible cause of severe acute respiratory syndrome. Lancet 361:13191325

Pervushin K, Tan E, Parthasarathy K, Lin X, Jiang FL, Yu D, Vararattanavech A, Soong TW, Liu DX, Torres J (2009) Structure and inhibition of the SARS coronavirus envelope protein ion channel. PLoS Pathog 5:e1000511

Pewe L, Wu GF, Barnett EM, Castro RF, Perlman S (1996) Cytotoxic $\mathrm{T}$ cell-resistant variants are selected in a virus-induced demyelinating disease. Immunity 5:253-262

Pewe L, Xue S, Perlman S (1997) Cytotoxic T-cell-resistant variants arise at early times after infection in C57BL/6 but not in SCID mice infected with a neurotropic coronavirus. J Virol 71:7640 7647

Pewe L, Xue S, Perlman S (1998) Infection with cytotoxic Tlymphocyte escape mutants results in increased mortality and growth retardation in mice infected with a neurotropic coronavirus. J Virol 72:5912-5918

Pewe L, Heard SB, Bergmann C, Dailey MO, Perlman S (1999) Selection of CTL escape mutants in mice infected with a neurotropic coronavirus: quantitative estimate of TCR diversity in the infected central nervous system. J Immunol 163:6106-6113

Phares TW, Ramakrishna C, Parra GI, Epstein A, Chen L, Atkinson R, Stohlman SA, Bergmann CC (2009) Target-dependent B7-H1 regulation contributes to clearance of central nervous system infection and dampens morbidity. J Immunol 182:5430-5438
Phillips JJ, Chua MM, Lavi E, Weiss SR (1999) Pathogenesis of chimeric MHV4/MHV-A59 recombinant viruses: the murine coronavirus spike protein is a major determinant of neurovirulence. J Virol 73:7752-7760

Phillips JJ, Chua M, Seo SH, Weiss SR (2001) Multiple regions of the murine coronavirus spike glycoprotein influence neurovirulence. J Neurovirology 7:421-431

Phillips JJ, Chua MM, Rall GF, Weiss SR (2002) Murine coronavirus spike glycoprotein mediates degree of viral spread, inflammation, and virus-induced immunopathology in the central nervous system. Virology 301:109-120

Piotrowski Y, Hansen G, Boomaars-van der Zanden AL, Snijder EJ, Gorbalenya AE (2009) Crystal structures of the X-domains of a Group-1 and a Group-3 coronavirus reveal that ADP-ribosebinding may not be a conserved property. Protein Sci 18:6-16

Putics A, Filipowicz W, Hall J, Gorbalenya AE, Ziebuhr J (2005) ADP-ribose-1"-monophosphatase: a conserved coronavirus enzyme that is dispensable for viral replication in tissue culture. $\mathrm{J}$ Virol 79:12721-12731

Putics A, Gorbalenya AE, Ziebuhr J (2006a) Identification of protease and ADP-ribose 1"-monophosphatase activities associated with transmissible gastroenteritis virus non-structural protein 3. J Gen Virol 87:651-656

Putics A, Slaby J, Filipowicz W, Gorbalenya AE, Ziebuhr J (2006b) ADP-ribose-1"-phosphatase activities of the human coronavirus 229E and SARS coronavirus X domains. Adv Exp Med Biol 581:93-96

Ramakrishna C, Stohlman SA, Atkinson RD, Shlomchik MJ, Bergmann CC (2002) Mechanisms of central nervous system viral persistence: the critical role of antibody and B cells. J Immunol 168:1204-1211

Ramakrishna C, Bergmann CC, Holmes KV, Stohlman SA (2004) Expression of the mouse hepatitis virus receptor by central nervous system microglia. J Virol 78:7828-7832

Ramakrishna C, Atkinson RA, Stohlman SA, Bergmann CC (2006) Vaccine-induced memory CD8+ $\mathrm{T}$ cells cannot prevent central nervous system virus reactivation. J Immunol 176:3062-3069

Rempel JD, Murray SJ, Meisner J, Buchmeier MJ (2004a) Mouse hepatitis virus neurovirulence: evidence of a linkage between $S$ glycoprotein expression and immunopathology. Virology 318:45-54

Rempel JD, Murray SJ, Meisner J, Buchmeier MJ (2004b) Differential regulation of innate and adaptive immune responses in viral encephalitis. Virology 318:381-392

Roth-Cross JK, Martinez-Sobrido L, Scott EP, Garcia-Sastre A, Weiss SR (2007) Inhibition of the IFN-\{alpha $\} /\{$ beta $\}$ response by mouse hepatitis virus (MHV) at multiple levels. J Virol 81:7189-7199

Roth-Cross JK, Bender SJ, Weiss SR (2008) Murine coronavirus mouse hepatitis virus is recognized by MDA5 and induces type I interferon in brain macrophages/microglia. J Virol 82:9829-9838

Saeki K, Ohtsuka N, Taguchi F (1997) Identification of spike protein residues of murine coronavirus responsible for receptor-binding activity by use of soluble receptor-resistant mutants. J Virol 71:9024-9031

Saeki K, Ohtsuka N, Taguchi F (1998) Isolation and characterization of murine coronavirus mutants resistant to neutralization by soluble receptors. Adv Exp Med Biol 440:11-16

Savarin C, Bergmann CC, Hinton DR, Ransohoff RM, Stohlman SA (2008) Memory CD4+ T-cell-mediated protection from lethal coronavirus encephalomyelitis. J Virol 82:12432-12440

Scott EP, Branigan PJ, Del Vecchio AM, Weiss SR (2008) Chemokine expression during mouse hepatitis virus-induced encephalitis: contributions of the spike and background genes. J Neurovirology 14:5-16

Shieh CK, Lee HJ, Yokomori K, La Monica N, Makino S, Lai MM (1989) Identification of a new transcriptional initiation site and 
the corresponding functional gene $2 \mathrm{~b}$ in the murine coronavirus RNA genome. J Virol 63:3729-3736

Smits SL, Gerwig GJ, van Vliet AL, Lissenberg A, Briza P, Kamerling J, Vlasak R, de Groot RJ (2005) Nidovirus sialateO-acetylesterases: Evolution and substrate specificity of coronaand toroviral receptor-destroy enzymes. J Mol Biol 280:69336941

Snijder EJ, Bredenbeek PJ, Dobbe JC, Thiel V, Ziebuhr J, Poon LL, Guan Y, Rozanov M, Spaan WJ, Gorbalenya AE (2003) Unique and conserved features of genome and proteome of SARScoronavirus, an early split-off from the coronavirus group 2 lineage. J Mol Biol 331:991-1004

Sperry S, Kazi L, Graham R, Baric R, Weiss S, Denison M (2005) Single amino acid substitutions in non-structural ORF1b-nsp14 and ORF2a 30kDa proteins of the murine coronavirus MHV-A59 are attenuating in mice. J Virol 79:3391-3400

Stohlman SA, Weiner LP (1981) Chronic central nervous system demyelination in mice after JHM virus infection. Neurology 31:38-44

Stohlman SA, Brayton PR, Fleming JO, Weiner LP, Lai MM (1982) Murine coronaviruses: isolation and characterization of two plaque morphology variants of the JHM neurotropic strain. J Gen Virol 63:265-275

Stohlman SA, Bergmann CC, van der Veen RC, Hinton DR (1995) Mouse hepatitis virus-specific cytotoxic $\mathrm{T}$ lymphocytes protect from lethal infection without eliminating virus from the central nervous system. J Virol 69:684-694

Stohlman SA, Bergmann CC, Lin MT, Cua DJ, Hinton DR (1998) CTL effector function within the central nervous system requires CD4+ T cells. J Immunol 160:2896-2904

Stohlman SA, Hinton DR (2001) Viral induced demyelination. Brain Pathol 11(1):92-106

Stohlman SA, Hinton DR, Parra B, Atkinson R, Bergmann CC (2008) CD4 $T$ cells contribute to virus control and pathology following central nervous system infection with neurotropic mouse hepatitis virus. J Virol 82:2130-2139

Sturman LS, Holmes KV, Behnke J (1980) Isolation of coronavirus envelope glycoproteins and interaction with the viral nucleocapsid. J Virol 33:449-462

Sun N, Grzybicki D, Castro RF, Murphy S, Perlman S (1995) Activation of astrocytes in the spinal cord of mice chronically infected with a neurotropic coronavirus. Virology 213:482-493

Taguchi F, Siddell SG, Wege H, ter Meulen V (1985) Characterization of a variant virus selected in rat brains after infection by coronavirus mouse hepatitis virus JHM. J Virol 54:429-435

Taguchi F, Massa PT, ter Meulen V (1986) Characterization of a variant virus isolated from neural cell culture after infection of mouse coronavirus JHMV. Virology 155:267-270

Taguchi F, Matsuyama S (2002) Soluble receptor potentiates receptorindependent infection by murine coronavirus. J Virol 76:950-958

Tahara SM, Dietlin TA, Nelson GW, Stohlman SA, Manno DJ (1998) Mouse hepatitis virus nucleocapsid protein as a translational effector of viral mRNAs. Adv Exp Med Biol 440:313-318

Templeton SP, Kim TS, O'Malley K, Perlman S (2008) Maturation and localization of macrophages and microglia during infection with a neurotropic murine coronavirus. Brain Pathol 18:40-51

Tsai JC, Zelus BD, Holmes KV, Weiss SR (2003a) The N-terminal domain of the murine coronavirus spike glycoprotein determines the CEACAM1 receptor specificity of the virus strain. J Virol $77: 841-850$

Tsai JC, de Groot L, Pinon JD, Iacono KT, Phillips JJ, Seo SH, Lavi E, Weiss SR (2003b) Amino acid substitutions within the heptad repeat domain 1 of murine coronavirus spike protein restrict viral antigen spread in the central nervous system. Virology 312:369-380

Tschen SI, Bergmann CC, Ramakrishna C, Morales S, Atkinson R, Stohlman SA (2002) Recruitment kinetics and composition of antibody-secreting cells within the central nervous system following viral encephalomyelitis. J Immunol 168:2922-2929

van der Hoek L, Sure K, Ihorst G, Stang A, Pyrc K, Jebbink MF, Petersen G, Forster J, Berkhout B, Uberla K (2005) Croup is associated with the novel coronavirus NL63. PLoS Med 2:e240

Vennema H, Godeke GJ, Rossen JW, Voorhout WF, Horzinek MC, Opstelten DJ, Rottier PJ (1996) Nucleocapsid-independent assembly of coronavirus-like particles by co-expression of viral envelope protein genes. EMBO J 15:2020-2028

Wang FI, Stohlman SA, Fleming JO (1990) Demyelination induced by murine hepatitis virus JHM strain (MHV-4) is immunologically mediated. J Neuroimmunol 30:31-41

Wang FI, Fleming JO, Lai MM (1992) Sequence analysis of the spike protein gene of murine coronavirus variants: study of genetic sites affecting neuropathogenicity. Virology 186:742-749

Wathelet MG, Orr M, Frieman MB, Baric RS (2007) Severe acute respiratory syndrome coronavirus evades antiviral signaling: role of nsp1 and rational design of an attenuated strain. J Virol $81: 11620-11633$

Wege H, Dorries R, Wege H (1984) Hybridoma antibodies to the murine coronavirus JHM: characterization of epitopes on the peplomer protein (E2). J Gen Virol 65(Pt 11):1931-1942

Weiner LP (1973) Pathogenesis of demyelination induced by a mouse hepatitis. Arch Neurol 28:298-303

Weiner LP, Johnson RT, Herndon RM (1973) Viral infections and demyelinating diseases. N Engl J Med 288:1103-1110

Weiss SR, Navas-Martin S (2005) Coronavirus pathogenesis and the emerging pathogen severe acute respiratory syndrome coronavirus. Microbiol Mol Biol Rev 69:635-664

Williams RK, Jiang GS, Snyder SW, Frana MF, Holmes KV (1990) Purification of the 110-kilodalton glycoprotein receptor for mouse hepatitis virus (MHV)-A59 from mouse liver and identification of a nonfunctional, homologous protein in MHVresistant SJL/J mice. J Virol 64:3817-3823

Williams RK, Jiang GS, Holmes KV (1991) Receptor for mouse hepatitis virus is a member of the carcinoembryonic antigen family of glycoproteins. Proc Natl Acad Sci U S A 88:55335536

Williamson JS, Stohlman SA (1990) Effective clearance of mouse hepatitis virus from the central nervous system requires both CD4 + and CD8+ T cells. J Virol 64:4589-4592

Williamson JSP, Sykes KC, Stohlman SA (1991) Characterization of brain-infiltrating monuclear cells during infection with mouse hepatitis virus strain JHM. J Neuroimmunol 32:199-207

Wilson L, Gage P, Ewart G (2006) Hexamethylene amiloride blocks E protein ion channels and inhibits coronavirus replication. Virology 353:294-306

Wu GF, Perlman S (1999) Macrophage infiltration, but not apoptosis, is correlated with immune-mediated demyelination following murine infection with a neurotropic coronavirus. J Virol 73:8771-8780

Wu GF, Dandekar AA, Pewe L, Perlman S (2000) CD4 and CD8 T cells have redundant but not identical roles in virus-induced demyelination. J Immunol 165:2278-2286

Ye Y, Hauns K, Langland JO, Jacobs BL, Hogue BG (2007) Mouse hepatitis coronavirus A59 nucleocapsid protein is a type I interferon antagonist. J Virol 81:2554-2563

Yokomori K, La Monica N, Makino S, Shieh CK, Lai MM (1989) Biosynthesis, structure, and biological activities of envelope protein gp65 of murine coronavirus. Virology 173:683-691

Yokomori K, Banner LR, Lai MM (1991) Heterogeneity of gene expression of the hemagglutinin-esterase (HE) protein of murine coronaviruses. Virology 183:647-657

Yokomori K, Baker SC, Stohlman SA, Lai MM (1992) Hemagglutininesterase-specific monoclonal antibodies alter the neuropathogenicity of mouse hepatitis virus. J Virol 66:2865-2874 
Yokomori K, Stohlman SA, Lai MM (1993) The detection and characterization of multiple hemagglutinin-esterase (HE)-defective viruses in the mouse brain during subacute demyelination induced by mouse hepatitis virus. Virology 192:170-178

Yokomori K, Asanaka M, Stohlman SA, Makino S, Shubin RA, Gilmore W, Weiner LP, Wang FI, Lai MM (1995) Neuropathogenicity of mouse hepatitis virus JHM isolates differing in hemagglutinin-esterase protein expression. J Neurovirology $1: 330-339$

Yount B, Denison MR, Weiss SR, Baric RS (2002) Systematic assembly of a full-length infectious cDNA of mouse hepatitis virus strain A59. J Virol 76:11065-11078

Yu X, Bi W, Weiss SR, Leibowitz JL (1994) Mouse hepatitis virus gene $5 \mathrm{~b}$ protein is a new virion envelope protein. Virology 202:1018-1023
Zhao J, Zhao J, Perlman S (2009) De novo recruitment of antigenexperienced and naive $\mathrm{T}$ cells contributes to the long-term maintenance of antiviral $\mathrm{T}$ cell populations in the persistently infected central nervous system. J Immunol 183:5163-5170

Zheng D, Chen G, Guo B, Cheng G, Tang H (2008) PLP2, a potent deubiquitinase from murine hepatitis virus, strongly inhibits cellular type I interferon production. Cell Res 18:1105-1113

Zhou J, Stohlman SA, Hinton DR, Marten NW (2003) Neutrophils promote mononuclear cell infiltration during viral-induced encephalitis. J Immunol 170:3331-3336

Zust R, Cervantes-Barragan L, Kuri T, Blakqori G, Weber F, Ludewig B, Thiel V (2007) Coronavirus non-structural protein 1 is a major pathogenicity factor: implications for the rational design of coronavirus vaccines. PLoS Pathog 3:e109 